Staff Working Paper/Document de travail du personnel 2017-23

\title{
Understanding the Cross-Country Effects of US Technology Shocks
}

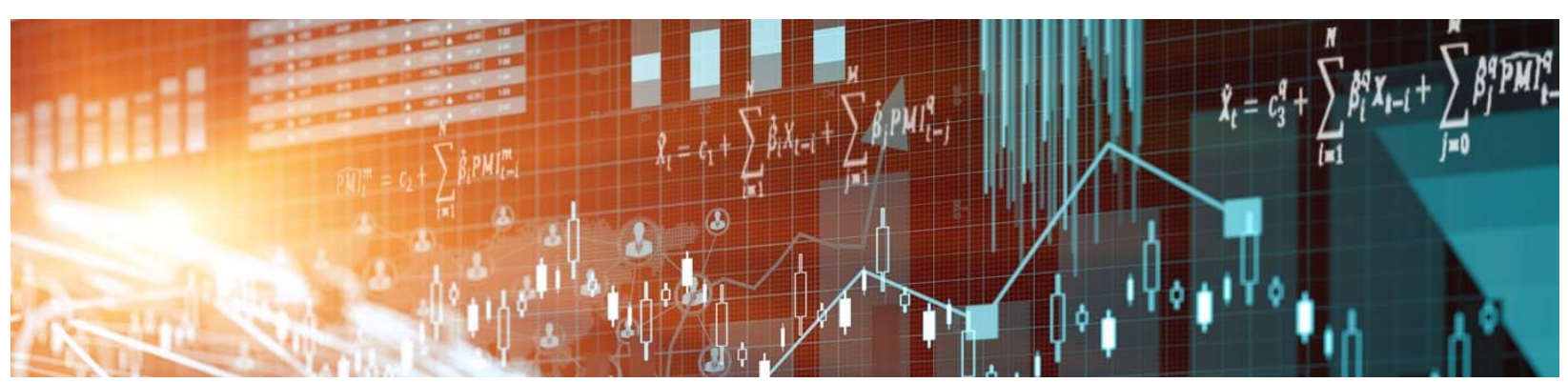

by Wataru Miyamoto and Thuy Lan Nguyen 
Bank of Canada Staff Working Paper 2017-23

June 2017

\title{
Understanding the Cross-Country Effects of US Technology Shocks
}

\author{
by \\ Wataru Miyamoto ${ }^{1}$ and Thuy Lan Nguyen ${ }^{2}$ \\ ${ }^{1}$ Canadian Economic Analysis Department \\ Bank of Canada \\ Ottawa, Ontario, Canada K1A OG9 \\ wmiyamoto@bankofcanada.ca \\ 2Santa Clara University \\ tlnguyen@scu.edu
}




\section{Acknowledgements}

We thank our advisors, Emi Nakamura, Stephanie Schmitt-Grohé, Jón Steinsson, and Martín Uribe, for their invaluable advice. We also thank the editor, the two anonymous referees, Jaromir Nosal, Tommaso Monacelli and Ricardo Reis for their comments, and the participants at the Columbia Economic Fluctuation, Monetary Colloquia, and other institutions for their inputs. The first draft of this paper was in January 2013. 


\begin{abstract}
Business cycles are substantially correlated across countries. Yet most existing models are not able to generate substantial transmission through international trade. We show that the nature of such transmission depends fundamentally on the features determining the responsiveness of labor supply and labor demand to international relative prices. We augment a standard international macroeconomic model to incorporate three key features: a weak short-run wealth effect on labor supply, variable capital utilization, and imported intermediate inputs for production. This model can generate large and significant endogenous transmission of technology shocks through international trade. We demonstrate this by estimating the model using data for Canada and the United States with limited-information Bayesian methods. We find that this model can account for the substantial transmission of permanent US technology shocks to Canadian aggregate variables such as output and hours, documented in a structural vector autoregression. Transmission through international trade is found to explain the majority of the business cycle co-movement between the United States and Canada.
\end{abstract}

Bank topics: Business fluctuations and cycles; Economic models; International topics JEL codes: F41, F44, F62, E30

\title{
Résumé
}

Les cycles économiques sont très fortement corrélés d'un pays à l'autre. Pour autant, la plupart des modèles n'arrivent pas à créer de transmission importante des cycles à travers les échanges internationaux. Nous montrons que la nature de cette transmission dépend essentiellement des caractéristiques qui gouvernent la réaction de l'offre de travail et de la demande de travail à l'évolution des prix relatifs internationaux. Nous ajoutons au modèle standard du cycle économique international trois éléments importants : un effet de richesse faible à court terme sur l'offre de travail, un taux d'utilisation variable du capital et des intrants intermédiaires importés pour la production. Ce modèle peut générer une transmission endogène de grande ampleur des chocs technologiques à travers les échanges internationaux. Nous démontrons cette caractéristique en estimant le modèle à partir de données canadiennes et américaines au moyen de techniques bayésiennes à information limitée. Nous constatons que le modèle parvient à rendre compte de l'effet important des chocs technologiques permanents survenus aux États-Unis sur des variables agrégées de l'économie canadienne, comme la production et les heures de travail, présentés dans un modèle vectoriel autorégressif structurel. La transmission par le 
canal des échanges internationaux permet d'expliquer l'essentiel des co-mouvements des cycles économiques des États-Unis et du Canada.

Sujets : Cycles et fluctuations économiques ; Modèles économiques ; Questions internationales

Codes JEL : F41, F44, F62, E30 


\section{Non-Technical Summary}

\section{Motivation and Question}

It is well documented that business cycles are substantially correlated across countries. Knowledge of why business cycles comove is important to understand the sources of business cycles in each country and to design external policies. One potential explanation for the observed comovements across countries is endogenous transmission; i.e., shocks propagating from one country to another country through international trade in goods and financial assets. Yet, most existing models in the international business cycle literature are not able to generate significant endogenous transmission. Given this problem in the literature, we ask what features of international business cycle models can generate substantial endogenous transmission across countries.

\section{Methodology}

First, we document the effects of identified permanent U.S. technology shocks on the Canadian output, consumption, investment, hours, net export, and terms of trade using structural vector autoregression (SVAR). We then augment a standard international business cycle model with three key features: variable capital utilization, imported intermediate inputs for production and household preferences that allow us to parameterize weak wealth effects on labor supply. Using Bayesian methods, we estimate this model to assess its ability to explain the transmission of U.S. technology shocks in Canada.

\section{Key Contributions}

We have two main contributions. First, we empirically characterize the transmission of technology shocks across countries. Second, we demonstrate that our model is able to generate substantial endogenous transmission and explain our empirical findings, in contrast to previous results in the literature.

\section{Findings}

Using our SVAR model, we find that positive U.S. technology shocks cause a significant boom in Canada and an improvement in its terms of trade. In particular, an increase of $1.0 \%$ in U.S. output driven by a permanent technology shock in the United States leads to an increase of about $0.6 \%$ in Canadian output and an improvement of about $1.0 \%$ in Canadian terms of trade. We also find that our estimated international business cycle model matches well with the results of our SVAR.

\section{Future Research}

Since our analysis suggests that simple modifications of standard international business cycles can generate substantial international transmission of shocks, our analysis can be extended to resolve the trade-comovement puzzle, which relates trade shares and output correlations across countries. Additionally, given that this paper focuses on conditional responses to technology shocks, future work should try to quantitatively account for the unconditional movements of both quantities and international relative prices by including other types of shocks. 


\section{Introduction}

It is widely documented that business cycles comove substantially across countries. Both output and hours are highly correlated across G7 countries in the business cycle frequency, averaged to be 0.54 and 0.45 , respectively. ${ }^{1}$ Knowledge of why business cycles comove is important to understand the sources of business cycles in each country and to design external policies. One potential explanation for the observed comovements across countries is endogenous transmission; i.e., shocks propagating from one country to another country through international trade in goods and financial assets. Yet, most existing models in the international business cycle literature are not able to generate significant endogenous transmission. International real business cycle models starting with Backus, Kehoe, and Kydland (1992) and Backus, Kehoe, and Kydland (1995) generate weak, or even negative correlation of key aggregate variables such as output and hours without correlated shocks. ${ }^{2}$

The New Open Economy Macroeconomics models, which extend the framework of Christiano, Eichenbaum, and Evans (2005) and Smets and Wouters (2007) to the open economy setting, have also been shown to face the same problem, namely that foreign shocks explain little of the domestic variables in their models. This type of model provides a surprisingly poor explanation of the endogenous transmission of foreign shocks to the domestic economy and the cross-country comovements of key macroeconomic variables although these models are judged as being adequate for explaining the effects of domestic shocks. ${ }^{3}$ The takeaway from the literature is that existing models do a poor job of explaining the comovements in the data through the endogenous transmission mechanism.

Given this state of the literature, the contribution of our paper is two-fold. First, we empirically characterize the transmission of shocks across countries. We document the effects of identified permanent U.S. technology shocks on not only the Canadian output, consumption, investment,

\footnotetext{
${ }^{1}$ We obtain G7 data from the International Financial Statistics for the period 1973Q1-2012Q2. The data are HP-filtered.

${ }^{2}$ A few examples are Stockman and Tesar (1995), Heathcote and Perri (2002), Ambler, Cardia, and Zimmermann (2002), and Baxter and Farr (2005). More recent papers in this literature include Engel and Wang (2011) and Johnson (2014). Schmitt-Grohé (1998) demonstrates that a class of real business cycle models cannot explain the observed dynamic effects of shocks to U.S. output on the Canadian economy through international trade and financial assets. We note that although Schmitt-Grohé (1998), Raffo (2008) and some other papers use the class of preferences with no wealth effects on labor supply, these papers still need correlated shocks in the model to explain the empirical correlations.

${ }^{3}$ Justiniano and Preston (2010) find that estimated international business cycle models with nominal rigidities also cannot generate substantial endogenous transmission and this class of models fails to explain both the documented importance of foreign shocks to domestic business cycles and the comovements of macroeconomic variables across countries. Other papers, such as Adolfson et al. (2007), Adolfson et al. (2008) and Christiano, Trabandt, and Walentin (2010), report a similar result.
} 
hours, and net export, but also the terms of trade. Second, we show that the nature of endogenous transmission depends fundamentally on the features determining the responsiveness of labor supply and labor demand to international relative prices. We incorporate three key features in a standard international business cycle model: Jaimovich-Rebelo preferences, variable capital utilization, and imported intermediate inputs for production. We estimate this model and demonstrate that it matches well with the empirical evidence, in contrast with the negative results in the literature.

In the empirical evidence, we identify the transmission mechanism of U.S. technology shocks to the Canadian economy. The reasons for our empirical approach are as follows. First, we focus on the conditional responses to a structural shock to clarify the transmission mechanism. The economy can be driven by several structural shocks, each of which may have different effects on the aggregate variables. For example, both foreign government spending shocks and foreign technology shocks can increase domestic output, but they have opposite effects on the terms of trade. While spending shocks depreciate the terms of trade, foreign technology shocks appreciate the terms of trade. So, a non-structural foreign shock that increases output can be a combination of these two structural shocks and have ambiguous effects on the terms of trade. If we focus only on nonstructural shocks, we may come to an incorrect conclusion about endogenous transmission in the model. ${ }^{4}$ Second, we analyze a small and large pair of countries, Canada and the United States, to identify exogenous shocks to the home country to examine its transmission mechanism. If both countries in consideration are large, the feedback between countries makes it difficult to pin down the transmission channel. Furthermore, shocks can propagate across countries both directly and indirectly through a third country. As the United States is the single most important trade partner for Canada, the U.S.-Canada pair can overcome these difficulties.

We identify permanent U.S. technology shocks using the long-run identification, which imposes that only permanent U.S. technology shocks can affect U.S. labor productivity in the long run. We find that our identified U.S. technology shocks cause a significant boom in Canada. ${ }^{5}$ Output in Canada increases by $60 \%$ of the increase in U.S. output. Hours worked in Canada increase by a magnitude similar to Canadian output, and the Canadian terms of trade appreciate. The responses are statistically significant, so we can use them to test the transmission mechanism in the model.

\footnotetext{
${ }^{4}$ An alternative approach is the full information estimation. This approach can increase the possibility of model misspecification as we would need to include several different types of shocks and frictions in both domestic and foreign countries to describe the full dynamics of the economy. By examining conditional responses, we can focus on testing the transmission mechanism.

${ }^{5}$ We also examine the transmission of permanent U.S. technology shocks on Mexico, and the main findings for Canada carry through to Mexico.
} 
On the theoretical side, we first analyze why standard international business cycle models cannot generate substantial endogenous transmission. We focus on the response of domestic hours because in the absence of a change in the level of domestic technology, increases in output require an increase in hours. When there is a positive permanent technology shock in the foreign country, the supply of foreign goods increases, causing the domestic terms of trade to appreciate. This appreciation of the domestic terms of trade affects both labor supply and labor demand in the domestic economy. In standard models, on the labor supply side, domestic households become richer and decrease their labor supply. On the labor demand side, for a given appreciation in the terms of trade, labor demand can increase. However, the increase in the labor demand may not be sufficient to overcome the decline in labor supply. Therefore, hours decrease in equilibrium, and standard models fail to generate strong endogenous transmission under plausible parameterizations. We further analyze the two common features in standard models in generating endogenous transmission: asset market completeness and the elasticity of substitution between domestic and foreign goods. It has been argued in the literature that these two features help standard models to replicate the observed consumption movement. However, to the extent that the terms of trade and consumption are matched with the data, the relationship between domestic hours and the terms of trade does not depend on either asset market completeness or the elasticity of substitution. A lower elasticity of substitution can generate larger transmission only because it causes larger movements of the terms of trade. These features cannot explain jointly the response of domestic hours to foreign shocks and the terms of trade, and endogenous transmission in these models is weak.

Second, to overcome the stark negative results in the literature, we incorporate compelling adjustments to a standard real international business cycle model to generate substantial endogenous transmission and explain the observed business cycle comovements. The model includes three key features: Jaimovich-Rebelo preferences, variable capital utilization, and imported intermediate inputs for production. The intuition for how these three key features help to generate substantial endogenous transmission is as follows. With Jaimovich-Rebelo preferences, which allow for a low wealth elasticity of labor supply, domestic labor supply does not decrease much. On the labor demand side, for a given appreciation in the terms of trade, the increase in labor demand can be substantially larger when there are both imported intermediate inputs and variable capacity utilization. The cheaper import prices cause domestic firms to increase the amount of imported intermediate inputs from the foreign country, increasing labor demand. Additionally, variable capital utilization amplifies the change in other inputs in the production function. In equilibrium, the 
three key features help to increase hours in the domestic economy, so output increases.

Finally, to assess the model's ability to explain our empirical evidence, we estimate standard international real business cycle models with and without the three features above. We match the theoretical impulse responses and their empirical counterparts using the limited-information Bayesian methods as in Christiano, Trabandt, and Walentin (2010). Consistent with our analysis, the model employing the three key features can explain the bulk of the transmission found in the data while the standard model cannot. Even when we allow the shocks to be correlated between the United States and Canada and estimate the correlation parameter, the marginal log likelihoods of the two estimated models suggest that the model with the three key features still matches better than the model without these features. Our estimation also suggests that the model with only one feature, such as no wealth effects, is not sufficient to generate substantial transmission as observed in the data.

Our proposed mechanism contributes to the broad international business cycles literature. For example, Corsetti, Dedola, and Leduc (2008a) and Burstein, Kurz, and Tesar (2008) propose two different mechanisms for shocks to transmit across countries. We need adjustments to the standard model other than the mechanisms in those papers to deliver the results consistent with our observed movements of both quantities and international relative prices. We note that while previous papers such as Mendoza (1991), Raffo (2008) and García-cicco, Pancrazi, and Uribe (2010) have used preferences with no wealth effects, we provide empirical evidence for weak wealth effects. Baxter and Farr (2005) include utilization in their one-good model. However, we show that utilization itself is not sufficient for endogenous transmissions. Although we use a small-large pair of countries to clarify the transmission channel, our proposed features can work in other international business cycle models including the standard two-large-country models. ${ }^{6}$ We also relate to the news shocks literature in an international context: the permanent U.S. technology shock process implies a gradual increase in productivity; we can interpret that our three key features are able to generate comovement in a slow diffusion of productivity across countries.

The remainder of the paper is organized as follows. Section 2 documents the empirical evidence

\footnotetext{
${ }^{6}$ We are also related to and contribute to a large international business cycle literature as we provide a unified framework that can generate substantial endogenous transmission of the cycle. Furthermore, we examine and match not only quantities but also the terms of trade across countries. We are also related to Hernandez and Leblebicioglu (2013) who highlight that the change in interest rate though working capital amplifies the effects of U.S. shocks on Mexico. However, we do not find that working capital plays any role in explaining the relationship between the United States and Canada. Additionally, we offer an explanation for how previous papers like Schmitt-Grohé (1998) and Justiniano and Preston (2010) fail to explain the observed effects of U.S. shocks on Canada. Finally, Enders and Müller (2009) examine empirically the movements of the terms of trade between the United States and a measure of the rest of the world, while we provide a clean exercise for two countries that are tightly linked.
} 
for the transmission of permanent U.S. technology shocks to Canada. We describe the baseline model in Section 3. Section 4 analyzes the transmission mechanism in the model. We estimate our model and present the results in Section 5. We discuss the sensitivity of each feature in the model in Section 6. Section 7 extends our analysis to a model with nominal rigidities. We conclude in Section 8 .

\section{Empirical Evidence}

In this section, we document the effects of U.S. permanent technology shocks on the Canadian economy using quarterly data for the United States and Canada in the post-Bretton Woods period between 1973Q1 and 2012Q3.

\subsection{The VAR Model}

We estimate a VAR model with U.S. and Canadian variables to identify permanent U.S. technology shocks using long-run restrictions. The VAR has two blocks: a U.S. block, $y_{1 t}$, and a Canadian block, $y_{2 t}$. U.S. block includes four variables: the growth rate of the labor productivity $\left(\Delta \ln \frac{y_{t}^{U . S .}}{h_{t}^{U . S . S}}\right)$, the natural logarithm of hours $\left(\ln h_{t}^{U . S .}\right)$, and the growth rates of consumption and investment $\left(\Delta \ln c_{t}^{U . S .}\right.$ and $\left.\Delta \ln I_{t}^{U . S .}\right)$. The Canadian block includes six variables: the growth rates of output, consumption, and investment; the natural logarithm of hours; the growth rate of the terms of trade; and the ratio of net exports to output. All variables are in real units and per capita for the period 1973Q1-2012Q3. ${ }^{7}$ Throughout the paper, the terms of trade are defined as the ratio of import price index to export price index, so a decline in the terms of trade means an appreciation for Canada.

Our identification strategy hinges on two assumptions. First, Canada is relatively small compared with the United States, and has no effects on the U.S. block. More specifically, we impose a block exogeneity of the following form:

$$
\left[\begin{array}{ll}
A_{11}(L) & A_{12}(L) \\
A_{21}(L) & A_{22}(L)
\end{array}\right]\left[\begin{array}{l}
y_{1 t} \\
y_{2 t}
\end{array}\right]=\left[\begin{array}{l}
e_{1 t} \\
e_{2 t}
\end{array}\right]
$$

\footnotetext{
${ }^{7}$ The data are from Statistics Canada, Organisation for Economic Co-operation and Development (OECD) National Accounts and the Bureau of Labor Statistics. The unit root and stationarity tests, which include the Augmented Dickey-Fuller (ADF) and KPSS tests on all U.S. and Canadian variables, suggest that productivity, consumption, output, investment, and the terms of trade to be used in log difference. For the ADF tests, we cannot reject that U.S. output, consumption, investment, Canadian output, consumption, investment, and terms of trade have a unit root with a $10 \%$ significance level. For KPSS tests, we can reject trend stationarity for the same variables. Hours in the United States and Canada are kept in level as there is no strong evidence of non-stationarity and in the model, hours are stationary. Over-differencing, as suggested by Christiano, Eichenbaum, and Vigfusson (2003) can cause model misspecification. Fisher (2006) also specifies hours in level in his empirical exercise.
} 
where the block exogeneity implies that:

$$
A_{12}(L)=0 \text { for } \forall L \text {. }
$$

This assumption has also been made in earlier works such as Schmitt-Grohé (1998) and Justiniano and Preston (2010), but they do not identify structural shocks.

Second, we identify U.S. permanent productivity shocks from U.S. block using the long-run restriction in Blanchard and Quah (1989) and Gali (1999); i.e., only permanent technology shocks can affect U.S. labor productivity in the long run. Specifically, U.S. block $y_{1 t}$ can be written as a distributed lag of technology and non-technology shocks, $\varepsilon_{1 t}^{U . S}$. and $\varepsilon_{2 t}^{U . S}$, which are orthogonal to each other:

$$
\left.y_{1 t}=\left[\begin{array}{c}
\Delta \ln \frac{y_{t}^{U . S .}}{h_{t}^{U . S .}} \\
\ln h_{t}^{U . S .} \\
\Delta \ln c_{t}^{U . S .} \\
\Delta \ln I_{t}^{U . S .}
\end{array}\right)\right]=\left[\begin{array}{ll}
C_{11}(L) & C_{12}(L) \\
C_{21}(L) & C_{22}(L)
\end{array}\right]\left[\begin{array}{l}
\varepsilon_{1 t}^{U . S .} \\
\varepsilon_{2 t}^{U . S .}
\end{array}\right] .
$$

The identification leads to the restriction that $C_{12}(1)=0$. We include four lags of each of the variables and a constant in the VAR model.

We then compute the impulse responses of all six variables in the Canadian block, $y_{2 t}$, following a one standard deviation shock in $\varepsilon_{1 t}^{U . S .}$. The dynamic responses are invariant to the ordering of the variables within $y_{2 t}$.

\subsection{The VAR Result}

The impulse response functions of all the variables for the United States are displayed in Figure 1 and for Canada in Figure 2. Lines marked with a plus sign correspond to the point estimate of the impulse responses, and the shaded areas are the $95 \%$ confidence band calculated from bootstrapping 1,000 times.

Our result suggests that after a positive permanent U.S. technology shock occurs in period 1:

1. U.S. output, consumption, investment and hours increase. ${ }^{8}$

2. All of the Canadian aggregate quantities go up and the terms of trade appreciate. Hours in Canada increase substantially, almost as much as Canadian output. Investment also increases and its highest response is twice as large as that of output. Consumption increases but by

\footnotetext{
${ }^{8}$ On impact, the response of hours is close to zero and insignificant.
} 

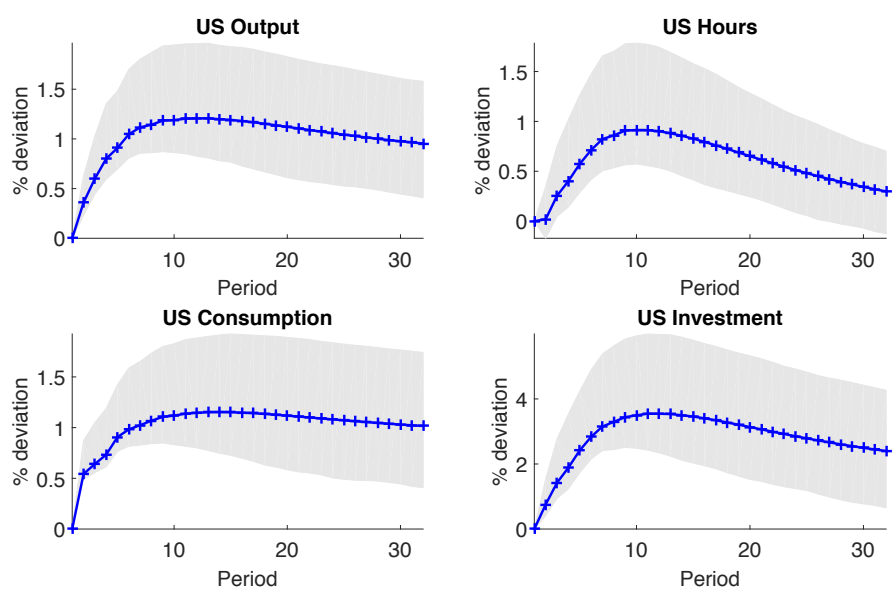

Figure 1: U.S. responses to a positive U.S. technology shock occurring in period 1. Lines with plus signs are the point estimates and the shaded areas are the $95 \%$ confidence intervals.

less than output. Canadian terms of trade appreciate slightly more than output. Net exports to output ratio in Canada increase significantly. The maximum response of net exports is about half of output. The boom in Canadian output at the maximum is as much as $60 \%$ of that of U.S. output.

3. Labor productivity increases slightly, about a fourth of Canadian output, but not significant at the $95 \%$ confidence level.

These results are different from Schmitt-Grohé (1998), who finds that the response of the terms of trade in Canada to an innovation to U.S. output is muted. One potential explanation for this difference is her empirical approach, which examines a non-structural U.S. output shock. As we argue above, a non-structural shock can be a combination of several structural shocks, so the analysis using a non-structural shock may lead to a different conclusion from when using a structural shock.

We perform a forecast error variance decomposition of these shocks on Canadian variables. As summarized in Table 1, the identified U.S. shocks explain a sizable fraction but not all of the business cycles in Canada. U.S. technology shocks contribute significantly to the fluctuations of all real variables, up to $39 \%$ of the Canadian output and $24 \%$ of hours at the eight-quarter horizon. The contribution to consumption in Canada is smaller: about $26 \%$ at the eight-quarter horizon and $35 \%$ at the 20 -quarter horizon. About $14 \%$ of investment and $19 \%$ of the terms of trade variation are explained by the identified permanent U.S. technology shock at the 20-quarter horizon, implying that other types of shocks are also important in driving these variables. These results suggest that 

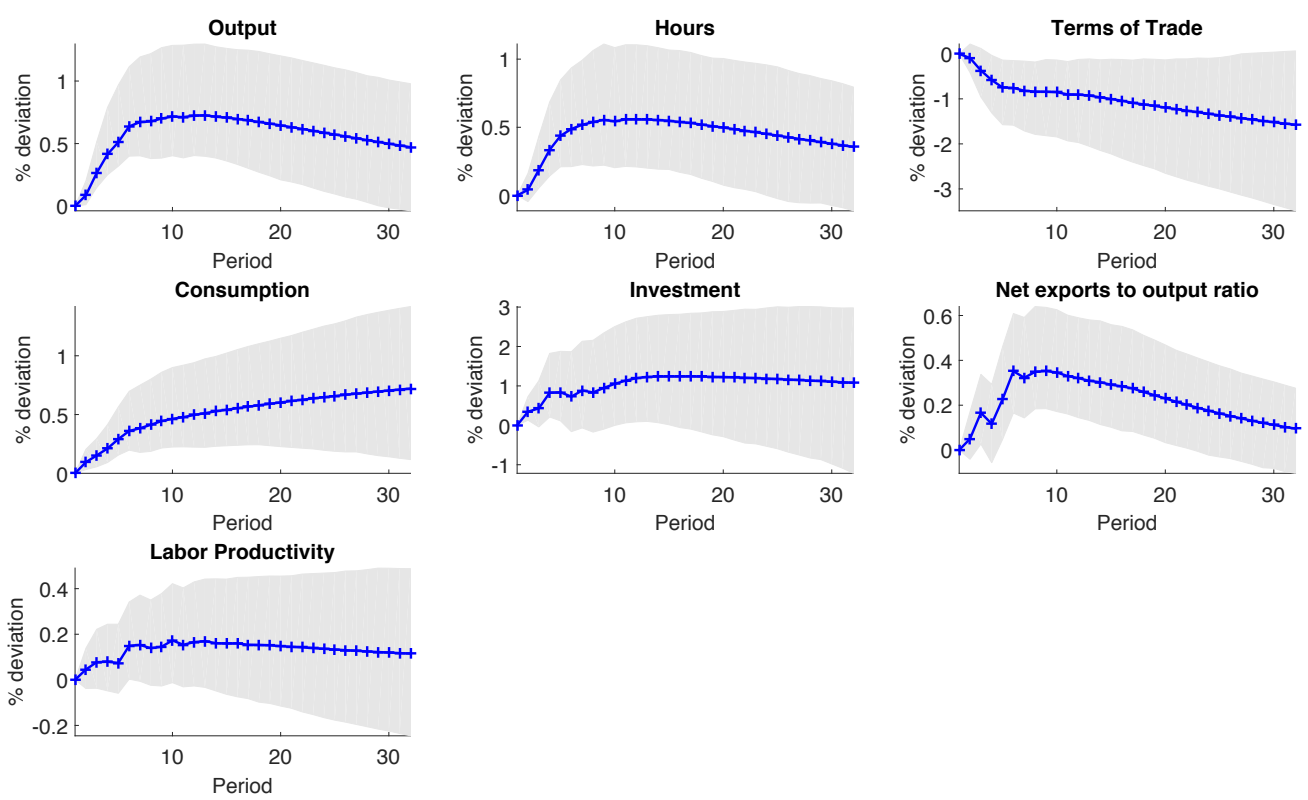

Figure 2: Canadian responses to a positive U.S. technology shock occurring in period 1. Lines with plus signs are the point estimates and the shaded areas are the $95 \%$ confidence intervals.

as permanent U.S. technology shocks are relatively important, we obtain a statistically significant estimated transmission of this shock. At the same time, permanent U.S. technology shocks do not explain a substantially large fraction of the volatilities of the macroeconomic variables, which supports our choice to focus on conditional responses to identified structural shocks.

\begin{tabular}{lcccc}
\hline & 2 quarters ahead & 4 quarters ahead & 8 quarters ahead & 20 quarters ahead \\
\hline Output & 0.12 & 0.23 & 0.39 & 0.52 \\
Consumption & 0.08 & 0.16 & 0.26 & 0.35 \\
Investment & 0.04 & 0.07 & 0.08 & 0.14 \\
Hours & 0.05 & 0.15 & 0.24 & 0.34 \\
Net exports to output & 0.04 & 0.07 & 0.23 & 0.4 \\
Terms of trade & 0.03 & 0.08 & 0.14 & 0.19 \\
\hline
\end{tabular}

Table 1: Forecast variance decomposition of Canadian variables conditional on permanent U.S. technology shocks.

These empirical results are robust to other VAR specifications and data. For example, we find a significant increase in both output and hours in Canada in response to a permanent U.S. technology shock identified from U.S. productivity and hours data in the manufacturing sector, similar to Corsetti, Dedola, and Leduc (2008b). This result holds if we replace U.S. labor productivity with total factor productivity data taken from Fernald (2014), or if we replace the terms of trade 
with the bilateral real exchange rate or the non-fuel terms of trade in the VAR. ${ }^{9}$ We run other robustness checks using other data specifications. ${ }^{10}$ In all of these cases, the results are similar to the findings above. We also estimate the baseline empirical specification for two subsamples: before the Great Recession (1973Q1-2006Q4) and after joining the North American Free Trade Agreement (NAFTA) (1994Q1-2012Q3). The responses of Canadian output and hours to permanent U.S. technology shocks are significant in both subsamples, and even stronger in the 1994Q1-2012Q3 sample, suggesting that trade may be an important transmission channel.

To check whether the transmission mechanism we documented is specific to the United States and Canada, we examine the effects of the identified U.S. technology shocks on Mexico, whose major trading partner is the United States. The detailed results are presented in Appendix Section A.6. The relative magnitudes of the responses of Mexican macroeconomic variables are similar to the results for Canada.

In the final robustness exercise, we identify both permanent U.S. technology shocks and U.S. investment-specific technology shocks, as in Fisher (2006). We summarize the detailed results in Appendix Section A.7. The conclusion from this exercise is that the Canadian responses to permanent U.S. technology shocks are qualitatively similar to the baseline. ${ }^{11}$

\subsection{U.S. and Canadian Technology Processes}

Are the effects of permanent U.S. technology shocks on Canada documented above a product of technology spillover? One way to empirically diagnose if U.S. and Canadian technology shocks are common is to compute the correlation between identified permanent U.S. and Canadian technology shocks. To this end, we apply the same long-run identification to Canadian labor productivity growth, hours, consumption and investment growth rates to extract permanent Canadian technology shocks. The contemporaneous correlation between the identified permanent Canadian and U.S. shocks is negative and insignificant (-0.07); the correlation is only significant and positive at lag six and negative for lag nine. ${ }^{12}$ This result provides little support for a strong exogenous correlation

\footnotetext{
${ }^{9}$ We find that real exports and imports of machinery, automotive and industrial goods in Canada respond to this U.S. shock more strongly than energy products, which suggests that the shocks we recover are not oil price shocks. Oil price can be an important factor in explaining the movements of Canadian terms of trade but not the conditional responses that we focus on.

${ }^{10}$ Other data specifications are to use output, investment, consumption and the terms of trade in log level instead of $\log$ difference, or the ratios of consumption to output and investment to output.

${ }^{11}$ We plot the responses of Canadian variables to U.S. investment-specific technology shocks. The details are available in the Appendix Figure A9.

${ }^{12}$ The five-quarter centered moving average of Canadian and U.S. shocks are positively but insignificantly correlated contemporaneously and up to five lags (0.10).
} 
component in the shock processes of these two countries in the short run.

Technology can also spill over directly and gradually if there is some cointegrating relationship between the United States and Canada. To check this possibility, we test for cointegration between outputs in both countries. Table 2 reports the results from the unrestricted cointegration rank test using the trace and maximum eigenvalue methods following Johansen (1991) with four lags and a constant in the cointegrating vector. All test statistics provide no strong evidence supporting or rejecting cointegration between U.S. and Canadian output. Using the same tests for Canadian and U.S. Solow Residuals, we find that there might be one cointegration relationship between U.S. and Canadian Solow residuals, but this result depends on the test statistics.

\begin{tabular}{cccccc}
\hline Number of vectors & Eigenvalue & Trace & $5 \%$ critical value & Max-eigenvalue & $5 \%$ critical value \\
\hline 0 & & 5.72 & 15.41 & 5.43 & 14.07 \\
1 & 0.1 & 0.28 & 3.76 & 0.28 & 3.76 \\
\hline
\end{tabular}

Table 2: Cointegration statistics: Johansen's test for output.

Overall, these results suggest that the strong comovement between the United States and Canada in response to a U.S. technology shock should, at least to some extent, come from international goods and financial trade rather than only from correlated shocks. At the same time, there might be some slow diffusion of technology from the United States to Canada. ${ }^{13}$ To quantify the importance of spillover compared with transmission through international trade, Section 6.3 estimates the model with the cointegrating relationship in the technology process to let the data decide, and examines how technology diffusion changes the model implication about the responses of the Canadian economy.

\section{The Model}

This section details our baseline model, which builds on Backus, Kehoe, and Kydland (1995). The model is the limit of a two-country model in which Canada is a small open economy and the United States is a large closed economy. In this setup, Canada plays no role in explaining U.S. aggregate variables. This assumption is consistent with our VAR specification. ${ }^{14}$

Our main departure from standard international real business cycle models is that we include three features in the model. These three key features are the Jaimovich-Rebelo utility function, variable capital utilization, and imported intermediate inputs. These features, as we later show, are

\footnotetext{
${ }^{13}$ One can interpret this shock as news for Canada.

${ }^{14}$ We also estimate a two-country model calibrated to the sizes of the United States and Canada. The results in the paper do not change.
} 
key to generating sufficiently strong endogenous transmission of technology shocks across countries. Other features in the model include incomplete financial markets in which agents can trade oneperiod non-contingent bonds, and an investment adjustment cost and a debt elastic interest rate. ${ }^{15}$

We describe the model below. Country 1, or home country, is a small open economy, and country 2 , or the foreign country, is a large closed economy version of country 1.

\section{$3.1 \quad$ Households}

Households in country 1 maximize the expected lifetime utility:

$$
\max E_{0} \sum_{t=0}^{\infty} \beta^{t} \frac{\left[C_{1 t}-\phi_{1}^{H} \frac{1}{1+\frac{1}{v}} X_{1 t} H_{1 t}^{1+\frac{1}{v}}\right]^{1-\sigma}-1}{1-\sigma}
$$

where subscript 1 denotes country $1, C_{1 t}$ is consumption, $H_{1 t}$ is hours worked in country 1 at time $t$, the parameter $\beta \in(0,1)$ is the subjective discount factor, and $\sigma>0$. The parameter $v>0$ is related to the Frisch elasticity of labor supply. $X_{1 t}$ satisfies the following equation:

$$
X_{1 t}=\left(C_{1 t}\right)^{\kappa_{1}} X_{1 t-1}^{1-\kappa_{1}} .
$$

This preference specification is introduced by Jaimovich and Rebelo (2009). The parameter $\kappa_{1}$ governs the wealth elasticity of labor supply. When $\kappa_{1}=1$, the preference is the common King, Plosser, and Rebelo (1988) (KPR) utility function. As $\kappa_{1} \rightarrow 0$, the utility function is the Greenwood, Hercowitz, and Huffman (1988) (GHH) preferences. In that case, there is no wealth effect on labor supply.

We assume that households can trade one-period non-contingent bonds denominated in foreign consumption, $B_{1 t+1}^{F}$, paid with interest rate $R_{1 t}^{F}$. To ensure a well-defined steady state and stationarity in the model, we assume a debt elastic interest rate of the form:

$$
R_{1 t}^{F}=R_{2 t}^{F} A\left(q_{t} B_{t+1}^{F} \frac{1}{Z_{1 t}}\right)
$$

where $R_{1 t}^{F}$ is the interest rate that country 1 needs to pay and $R_{2}^{F}$ is the interest rate in country 2 . $q_{t} B_{1 t+1}^{F} \frac{1}{Z_{1 t}}$ is the real foreign asset position where $q_{t}$ is the real exchange rate, defined as the relative price of foreign consumption goods in terms of home consumption goods, and $Z_{1 t}$ is the technology

\footnotetext{
${ }^{15}$ Investment adjustment costs can be important for matching investment volatility. A debt elastic interest rate is to ensure stationarity in incomplete financial market models. Both features are commonly used in the literature.
} 
level in country 1. Following Schmitt-Grohé and Uribe (2003) and Adolfson et al. (2007), we assume that the functional form of $A$ is given by:

$$
A\left(q_{t} B_{t+1}^{F} \frac{1}{Z_{1 t}}\right)=\exp \left[-\phi_{1}^{B}\left(\frac{q_{t} \frac{B_{t+1}^{F}}{Z_{1 t}}}{\left(\frac{q_{t} B_{t+1}^{F}}{Z_{1 t}}\right)_{s s}}-1\right)\right]
$$

where $\left(\frac{q_{t} B_{t+1}^{F}}{Z_{1 t}}\right)_{s s}$ is the steady state real foreign asset position.

Household is assumed to own capital $K_{1 t}$, which evolves over time under the following law of motion:

$$
K_{1 t+1}=\left(1-\delta\left(u_{1 t}\right)\right) K_{1 t}+I_{1 t}\left(1-S\left(\frac{I_{1 t}}{I_{1 t-1}}\right)\right)
$$

where $\delta\left(u_{t}\right)$ is the depreciation rate of capital which depends on the capital utilization $u_{1 t}$ and $I_{1 t}$ is the gross investment. We assume that increasing the intensity of capital utilization comes with a larger depreciation rate. The functional form for $\delta\left(u_{1 t}\right)$ is given by:

$$
\delta\left(u_{1 t}\right)=\delta_{0}+\delta_{11}\left(u_{1 t}-1\right)+\frac{\delta_{21}}{2}\left(u_{1 t}-1\right)^{2}
$$

with $\delta_{0}, \delta_{11}, \delta_{21}>0$. $\frac{\delta_{21}}{\delta_{11}}$ governs the sensitivity of the utilization to variations in the rental rate of capital. $\delta_{0}$ is the depreciation rate corresponding to the steady state where $u_{1 t}$ is unity. Following Christiano, Eichenbaum, and Evans (2005), we assume that it is costly to adjust the level of investment for capital; i.e., $S\left(\right.$.) is the adjustment cost satisfying $S\left(\mu_{1}\right)=0, S^{\prime}\left(\mu_{1}\right)=0, S^{\prime \prime}\left(\mu_{1}\right)=$ $s_{1}$, where $\mu_{1}$ is the steady state growth rate of output. We use the standard quadratic specification of $S$ as follows:

$$
S\left(\frac{I_{1 t}}{I_{1 t-1}}\right)=\frac{s_{1}}{2}\left(\frac{I_{1 t}}{I_{1 t-1}}-\mu_{1}\right)^{2}
$$

The household budget constraint is then given by:

$$
C_{1 t}+p_{1 t}^{I} I_{1 t}+B_{1 t+1}^{D} \frac{1}{R_{t}^{D}}+q_{t} B_{1 t+1}^{F} \frac{1}{R_{1 t}^{F}} \leq W_{1 t} H_{1 t}+R_{1 t}^{k}\left(u_{1 t} K_{1 t}\right)+B_{1 t}^{D}+q_{t} B_{1 t}^{F},
$$

where $p_{1 t}^{I}$ is the relative price of investment goods in terms of consumption goods. $B_{1 t+1}^{D}$ is the domestic bond with interest rate $R_{t}^{D}, W_{1 t}$ is the real wage, and $R_{1 t}^{k}$ is the real return to capital in terms of the home consumption goods unit. 


\subsubsection{Intermediate Good Producer}

The intermediate good producer in country 1 specializes in the production of home goods $Y_{t}^{D}$ by combining capital service, $u_{1 t} K_{1 t}$, labor, $H_{1 t}$, and imported and domestic intermediate inputs, $M_{21 t}$ and $M_{11 t}$, respectively, using the production function:

$$
Y_{1 t}=\left(\left(u_{1 t} K_{1 t}\right)^{\alpha}\left(Z_{1 t} H_{1 t}\right)^{1-\alpha}\right)^{1-\alpha_{11}-\alpha_{21}}\left(M\left(M_{11 t}, M_{21 t}\right)\right)^{\alpha_{11}+\alpha_{21}}
$$

where $\alpha_{11}>0$ and $\alpha_{21}>0$ are the shares of domestic and imported intermediate inputs in gross output, respectively, $\alpha\left(1-\alpha_{11}-\alpha_{21}\right)>0$ is the capital share, and $M\left(M_{11 t}, M_{21 t}\right)$ is the composite of home and imported intermediate good. Roundabout production is introduced to capture the role of intermediate inputs in production and cross-border trade. The functional form of $M($.$) is$ given as follows:

$$
M_{1 t}=\left(\left(\alpha_{11}\right)^{\frac{1}{\gamma_{1}}}\left(M_{11 t}\right)^{\frac{\gamma_{1}-1}{\gamma_{1}}}+\left(\alpha_{21}\right)^{\frac{1}{\gamma_{1}}}\left(M_{21 t}\right)^{\frac{\gamma_{1}-1}{\gamma_{1}}}\right)^{\frac{\gamma_{1}}{\gamma_{1}-1}}
$$

where $\gamma_{1}$ is the elasticity of substitution across domestic and foreign intermediate inputs.

The goods produced domestically, $Y_{1 t}$, can be sold to the domestic final good producer to make domestic consumption and investment goods, or used as an intermediate good in the production, or sold to the foreign country for its consumption, investment goods and production.

\subsubsection{Final Good Producer}

The final good producer in the small open economy imports foreign consumption $F_{1 t}^{C}$ and investment $F_{1 t}^{I}$ goods from the foreign producer at price $P_{1 t}^{F}$. The final good producer also buys domestic consumption $D_{1 t}^{C}$ and investment $D_{1 t}^{I}$ input from the intermediate good producer at price $P_{1 t}^{D}$. We assume that the law of one price holds.

The final good producer combines domestic and foreign inputs to produce final consumption using the following aggregator:

$$
C_{1 t}=\left(\left(\omega_{1}^{C}\right)^{\frac{1}{\gamma_{1}}}\left(D_{1 t}^{C}\right)^{\frac{\gamma_{1}-1}{\gamma_{1}}}+\left(1-\omega_{1}^{C}\right)^{\frac{1}{\gamma_{1}}}\left(F_{1 t}^{C}\right)^{\frac{\gamma_{1}-1}{\gamma_{1}}}\right)^{\frac{\gamma_{1}}{\gamma_{1}-1}}
$$

where $\omega_{1}^{C}>0$ is the home bias parameter for consumption goods. The final consumption good price is then defined as follows:

$$
P_{1 t}=\left(\omega_{1}^{C}\left(P_{1 t}^{D}\right)^{1-\gamma_{1}}+\left(1-\omega_{1}^{C}\right)\left(P_{1 t}^{F}\right)^{1-\gamma_{1}}\right)^{\frac{1}{1-\gamma_{1}}}
$$


The final good producer also produces investment goods in the same way as consumption goods; i.e.:

$$
I_{1 t}=\left(\left(\omega_{1}^{I}\right)^{\frac{1}{\gamma_{1}}}\left(D_{1 t}^{I}\right)^{\frac{\gamma_{1}-1}{\gamma_{1}}}+\left(1-\omega_{1}^{I}\right)^{\frac{1}{\gamma_{1}}}\left(F_{1 t}^{I}\right)^{\frac{\gamma_{1}-1}{\gamma_{1}}}\right)^{\frac{\gamma_{1}}{\gamma_{1}-1}},
$$

where $\omega_{1}^{I}>0$ is the home bias parameter for investment goods. For simplicity, we assume that the elasticities of substitution between home and foreign goods for consumption, intermediate and investment goods are the same. ${ }^{16}$ Similar to the price of consumption goods, the investment good price is

$$
P_{1 t}^{I}=\left(\omega_{1}^{I}\left(P_{1 t}^{D}\right)^{1-\gamma_{1}}+\left(1-\omega_{1}\right)\left(P_{1 t}^{F}\right)^{1-\gamma_{1}}\right)^{\frac{1}{1-\gamma_{1}}}
$$

The final good producer then sells consumption $C_{1 t}$ and investment $I_{1 t}$ to households. The final good producer's problem is to choose domestic and foreign inputs to maximize his profits, which yields the following set of demands for each domestic and foreign consumption and investment goods:

$$
\begin{array}{ll}
D_{1 t}^{C}=\omega_{1}^{C}\left(p_{1 t}^{D}\right)^{-\gamma_{1}} C_{1 t}, & D_{1 t}^{I}=\omega_{1}^{I}\left(\frac{p_{1 t}^{D}}{p_{1 t}^{I}}\right)^{-\gamma_{1}} I_{1 t}, \\
F_{1 t}^{C}=\left(1-\omega_{1}^{C}\right)\left(p_{1 t}^{F}\right)^{-\gamma_{1}} C_{1 t}, & F_{1 t}^{I}=\left(1-\omega_{1}^{I}\right)\left(\frac{p_{1 t}^{F}}{p_{1 t}^{I}}\right)^{-\gamma_{1}} I_{1 t},
\end{array}
$$

where the small letter $p$ denotes relative price to the final consumption good price $P_{1 t}$.

\subsection{Technology Process}

As in Rabanal, Rubio-Ramírez, and Tuesta (2011), the technology process has a cointegrating relationship in order to model and match the permanent technology shocks in country 1 and country 2. The technology process additionally includes a spillover parameter that governs the contemporaneous effect of country 2 to country 1 through the correlation of shocks. Canada is small relative to the United States, so we assume that there is no feedback from country 1 to country 2. We note that since there is no strong evidence supporting or rejecting cointegration and spillover in the data, we set the cointegration parameter close to 0 and the spillover parameter to 0 in the baseline. This parameterization is only to ensure a balanced growth path. We examine how changes in these two parameters affect the transmission in the robustness check. The technology process for country 1 is then described by:

$$
\Delta \ln Z_{1 t}=\mu_{1}+\zeta\left[\ln Z_{2 t-1}-\ln Z_{1 t-1}\right]+e_{1 t}
$$

\footnotetext{
${ }^{16}$ The different aggregations between investment, consumption and intermediate goods allow us to match the model with the data more closely than Backus, Kehoe, and Kydland (1995).
} 
When the technology differential $\frac{Z_{2 t-1}}{Z_{1 t-1}}$ is smaller than the long-run value, $\zeta>0$ ensures that $\Delta \ln Z_{1 t}$ will increase eventually so that we obtain a balanced growth path. This specification implies that $\Delta \ln Z_{1 t}$ and $\frac{Z_{2 t}}{Z_{1 t}}$ are stationary processes and $\zeta$ governs the speed at which the technology ratio $\frac{Z_{2 t}}{Z_{1 t}}$ goes back to the long-run value.

Country 2 is a closed economy, so the technology growth rate follows an autoregressive AR(1) process given by:

$$
\Delta \ln Z_{2 t}=\mu_{2}+\rho_{2} \Delta \ln Z_{2 t-1}+e_{2 t} .
$$

The innovations of technology for these two countries, $e_{1 t}$ and $e_{2 t}$, respectively, have the following relationship:

$$
\left(\begin{array}{c}
e_{1 t} \\
e_{2 t}
\end{array}\right)=A\left(\begin{array}{l}
v_{1 t} \\
v_{2 t}
\end{array}\right), v_{t} \sim N(0, I) \text {, and } A \equiv\left(\begin{array}{cc}
\bullet & \tau \sigma_{2} \\
\bullet & \sigma_{2}
\end{array}\right),
$$

where $\tau$ measures the contemporaneous effects of country 2's shocks on country 1 . Since the paper focuses on how foreign shocks affect the domestic economy, we ignore the first column of $A$.

\subsection{Prices and Equilibrium}

The optimal conditions for domestic and foreign bond holdings place a restriction on the movements of the domestic interest rate. The terms of trade are defined as $T O T_{t}=\frac{p_{1 t}^{F}}{p_{1 t}^{D}}$, and the law of one price dictates that $p_{1 t}^{F}=q_{t}$.

We define GDP as gross output subtracting intermediate inputs at the steady state prices:

$$
G D P_{1 t}=Y_{1 t}-M_{11 t}-M_{21 t}
$$

Country 2 produces gross output $Y_{2 t}$, so its GDP is defined analogously:

$$
G D P_{2 t}=Y_{2 t}-M_{22 t}
$$

The model is closed with the exogenous foreign demands for home consumption $D_{2 t}^{C}$, investment 
$D_{2 t}^{I}$, and intermediate $M_{12 t}$ goods as follows:

$$
\begin{aligned}
D_{2 t}^{C} & =\left(1-\omega_{2}^{C}\right)\left(\frac{p_{1 t}^{D}}{q_{t}}\right)^{-\gamma_{2}} C_{2 t}, \\
D_{2 t}^{I} & =\left(1-\omega_{2}^{I}\right)\left(\frac{p_{1 t}^{D}}{q_{t}}\right)^{-\gamma_{2}} I_{2 t}, \\
M_{12 t} & =\frac{\alpha_{12}}{\alpha_{22}}\left(\frac{p_{1 t}^{D}}{q_{t}}\right)^{-\gamma_{2}} M_{22 t},
\end{aligned}
$$

where $\omega_{2}^{C}$ and $\omega_{2}^{I}$ are the home biases of consumption and investment goods in country $2, \gamma_{2}>0$ is the elasticity of substitution between home and foreign country in country 2 , and $C_{2 t}, I_{2 t}, M_{22 t}$ are consumption, investment and domestic intermediate inputs in country 2 , respectively.

Finally, the general equilibrium requires that all markets clear; i.e.:

$$
\begin{gathered}
D_{1 t}^{C}+D_{1 t}^{I}+D_{2 t}^{C}+D_{2 t}^{I}+M_{12 t}+M_{11 t}=Y_{1 t}, \\
C_{2 t}+I_{2 t}+M_{22 t}=Y_{2 t} .
\end{gathered}
$$

\section{Understanding the Transmission Mechanism}

This section examines how our model generates substantial transmission of shocks through international trade. We first analyze why standard international business cycle models do not match the data. We then discuss the three key features that can help to reconcile the model with the data.

\subsection{The Failure of Standard Models}

We analyze a standard international business cycle model by shutting down the three main features of the baseline model: the household has the standard KPR preferences, there is no variable capacity utilization, and there are no imported intermediate inputs.

Our analysis focuses on the response of domestic hours, as hours play a central role in the transmission of foreign shocks: in the absence of a change in the level of domestic technology, increases in output require an increase in hours. From the first-order conditions, the log deviation of hours can be expressed as follows:

$$
\widehat{H_{1 t}}=\frac{1}{\alpha+\frac{1}{v}}\left[-\widehat{C}_{1 t}-\left(1-\omega_{1}^{C}\right) \widehat{T O T}_{t}+(1-\alpha) \widehat{Z}_{1 t}+\alpha \widehat{K}_{1 t}\right]
$$

where the hatted variables denote log deviations from steady state. This equation allows us to 
decompose the movement of hours in the domestic economy into four components: the wealth effect from the change in consumption, the terms of trade effect, the effect from the domestic technology change and the capital accumulation effect. To build intuition, we ignore the effect of capital accumulation since it is quantitatively small in the short run. When there is no exogenous correlation of technology shocks, i.e., $\widehat{Z}_{1 t}=0$, hours in the domestic economy can increase only if

$$
\widehat{C_{1 t}}<-\left(1-\omega_{1}^{C}\right) \widehat{T O T_{t}}
$$

This expression implies that the standard model may be able to generate an increase in hours, but it depends quantitatively on the relative movements of consumption and a fraction $1-\omega_{1}^{C}$ of the terms of trade. Since the home bias for consumption goods parameter $\omega_{1}^{C}$ is large in the data for most countries, including Canada, the terms of trade have to appreciate much more than the increase in consumption. Intuitively, the equilibrium hours depend on the movements of both labor demand and labor supply. A positive foreign technology shock causes the terms of trade to appreciate, so consumption increases, and labor supply decreases due to the wealth effect. On the labor demand side, an appreciation in the terms of trade implies that domestic goods are more expensive than domestic consumption goods because households consume both domestic and foreign goods, and then labor demand can increase. Therefore, the equilibrium hours can increase only if the increase in labor demand is large enough to overcome the decline in labor supply.

In the Canadian case, consumption increases by about $0.3 \%$ on average in the first five quarters after the shock, and the terms of trade appreciate by $0.6 \%$. This implies that Canadian hours can increase in this standard model if $\omega_{1}^{C}$ is smaller than 0.5 . However, $\omega_{1}^{C}$ is 0.9 in the data, so equation (14) implies that hours do not increase much, or even decrease in the short run. In Section 5.2 below, we estimate the standard model to demonstrate this analysis.

It is important to note that to the extent that the movements of consumption and the terms of trade are observed and replicated by the model, the analysis above does not depend on the features that have been highlighted in the previous literature. For example, asset market completeness as emphasized in Corsetti, Dedola, and Leduc (2008a) and Enders and Müller (2009) does not alter the relationship of hours and the terms of trade in equation (14). The reason we have a different mechanism compared with those papers is as follows. Corsetti, Dedola, and Leduc (2008a) propose that the standard model with incomplete markets together with a small elasticity of substitution can generate a depreciation in the terms of trade and a decrease in consumption after a foreign 
technology shock. Since equation (14) still holds in their case, hours can increase only if the decrease in consumption is large relative to the depreciation of the terms of trade. Calibrating to the unconditional second moments, Corsetti, Dedola, and Leduc (2008a) find that hours go down, so they rely on correlated shocks to generate positive comovement of output and consumption across countries in their model. Since we observe an increase in consumption and an appreciation in the terms of trade for Canada, we need a different mechanism to explain our empirical results.

Previous literature also suggests that the elasticity of substitution is important for standard models to generate large endogenous transmission. For example, in Burstein, Kurz, and Tesar (2008), a small elasticity of substitution, modeled as production sharing, can increase the output comovement across countries. The smaller the elasticity of substitution, the larger the complementarity between U.S. and Canadian goods, and the larger the movements of the terms of trade in response to U.S. technology shocks. In equation (14), this mechanism essentially changes the magnitude of the terms of trade response, so in theory, a smaller elasticity of substitution can help to generate a larger transmission of shocks across countries. However, if the model has to match the joint movements of the terms of trade, hours and consumption, as in our case, changing the elasticity of substitution may not be sufficient to explain our empirical results.

\subsection{How the Three Features Work}

We now discuss how the three key features work and interact with each other to generate substantial endogenous transmission through international trade.

First, the Jaimovich-Rebelo preference specification is an important feature as it allows us to adjust the strength of the wealth effect on labor supply. A small wealth effect can minimize the movement of the labor supply so that a small increase in the labor demand can increase hours in equilibrium. To see this, assuming that there is no wealth effect on labor supply, equation (14) can be rewritten as:

$$
\widehat{H}_{1 t}=\frac{1}{\alpha+\frac{1}{v}}\left[-\left(1-\omega_{1}^{C}\right) \widehat{T O T}_{t}+(1-\alpha) \widehat{Z}_{1 t}+\alpha \widehat{K}_{1 t}\right] .
$$

Since consumption does not appear in this equation, domestic hours can go up without any change in technology and capital as long as the terms of trade appreciate. Therefore, shutting down the wealth effect can help increase endogenous transmission within the model substantially, consistent with the intuition above.

Second, imported intermediate inputs help to increase the responsiveness of labor demand 
to the movement of the relative price of domestic goods. When the terms of trade appreciate, imported intermediate goods become relatively cheaper. Since domestic firms are able to use cheaper imported inputs from the foreign country to produce the goods with higher prices, the change in the terms of trade shifts the labor demand curve further. Given that a large share of international trade in most countries, including Canada, is in intermediate goods, the imported intermediate input channel can be quantitatively important. ${ }^{17}$

Finally, variable capacity utilization is important for amplifying the effects of the change in the terms of trade on hours worked. Combining the first-order conditions, assuming no wealth effects on labor supply and no intermediate inputs,

$$
\phi_{H} H_{t}^{\frac{1}{v}}=p_{t}^{D}(1-\alpha)\left(u_{t} K_{t}\right)^{\alpha}\left(Z_{t} H_{t}\right)^{-\alpha},
$$

implies that an increase in utilization increases labor demand further. Therefore, utilization can increase the response of hours substantially.

We quantify the importance of these features in generating endogenous transmission and justify these features by looking at the data in the next sections.

\footnotetext{
${ }^{17}$ To see this, we assume for simplicity that there is no wealth effect on labor supply and combine the first-order conditions to get:

$$
\widehat{H}_{1 t}=\frac{1}{\alpha+\frac{1}{v}}\left(-\left[\left(1-\omega_{1}^{C}\right)+\frac{\alpha_{21}}{1-\alpha_{11}-\alpha_{21}}\right] \widehat{T O T}_{t}+(1-\alpha) \widehat{Z}_{1 t}+\alpha \widehat{K}_{1 t}\right) .
$$

The additional term, $\frac{\alpha_{21}}{1-\alpha_{11}-\alpha_{21}} \widehat{T O T}_{t}$, compared with equation (15), shows the effects of intermediate inputs on hours worked.

A more general production function form with a constant elasticity of substitution between home and intermediate goods is:

$$
\begin{gathered}
F\left(Z, K, H, M_{11}, M_{21}\right)=\left[\omega_{f}^{\frac{1}{\gamma_{f}}} f(Z, K, H)^{\frac{\gamma_{f}-1}{\gamma_{f}}}+\left(1-\omega_{f}\right)^{\frac{1}{\gamma_{f}}} M\left(M_{11}, M_{21}\right)^{\frac{\gamma_{f}-1}{\gamma_{f}}}\right]^{\frac{\gamma_{f}}{\gamma_{f}-1}}, \\
M\left(M_{11}, M_{21}\right)=\left[\omega_{m}^{\frac{1}{\gamma_{m}}} M_{11}^{\frac{\gamma m-1}{\gamma m}}+\left(1-\omega_{m}\right)^{\frac{1}{\gamma_{m}}} M_{21}^{\frac{\gamma m-1}{\gamma m}}\right]^{\frac{\gamma_{m}}{\gamma_{m}-1}},
\end{gathered}
$$

where $\gamma_{f}$, and $\gamma_{m}$ denote the elasticities of substitution between home-produced and intermediate inputs, and between domestic and foreign intermediate inputs, respectively. We can show that for a given movement in the terms of trade, the movement of hours is affected only by the share of intermediate and imported intermediate inputs as follows:

$$
\widehat{H}_{t}=\frac{1}{\alpha+\frac{1}{v}}\left[-\left(1-\omega_{C}\right) \widehat{T O T}_{t}-\frac{\left(1-\omega_{f}\right)}{\omega_{f}}\left(1-\omega_{m}\right) \widehat{T O T}_{t}+(1-\alpha) \widehat{Z}_{1 t}+\alpha \widehat{K}_{1 t}\right]
$$
}




\section{Estimation}

Since the analysis in the previous section focuses on hours movements assuming that we can match the movements of the terms of trade, this section quantitatively evaluates the fitness of our model. We find that our estimated model matches both the responses of hours and the terms of trade, and it can generate substantial transmission through international trade.

\subsection{Estimation Method}

We calibrate the parameters that are related to the steady state and are commonly used in the literature. The rest of the parameters are estimated using limited-information Bayesian methods.

\subsubsection{Calibration}

Table 3 displays our calibrated parameters. We set the risk aversion parameter, $\sigma$, to be 2 , which is standard in the business cycle literature such as Backus, Kehoe, and Kydland (1995). The capital share is set to be 0.36 . The steady state depreciation rate, $\delta_{0}$, is assumed to be 0.025 , which means that about $10 \%$ of capital depreciates annually. Following García-cicco, Pancrazi, and Uribe (2010), we set $v$ to be 1.6. The debt adjustment parameter, $\phi_{D}$, is assumed to be 0.001 as in the small open economy literature, only to induce stationarity.

\begin{tabular}{llc}
\hline & Parameter & Value \\
\hline$\beta$ & Discount parameter & 0.99 \\
$\sigma$ & Risk aversion & 2 \\
$\phi_{D}$ & Debt elastic & 0.001 \\
$v$ & Governing Frisch elasticity & 1.6 \\
$\alpha$ & Capital share & 0.36 \\
$\delta$ & Depreciation rate of capital & 0.025 \\
$\mu_{1}$ & Steady state output growth in Canada & 1.0034 \\
$\mu_{2}$ & Steady state output growth in the United States & 1.0034 \\
$\alpha_{11}$ & Canadian intermediate share & 0.45 \\
$\alpha_{21}$ & Canadian imported intermediate share & 0.076 \\
$\alpha_{22}$ & U.S. intermediate share & 0.42 \\
$\omega_{1}^{C}$ & Consumption home bias & 0.90 \\
$\omega_{1}^{I}$ & Investment home bias & 0.77 \\
\hline
\end{tabular}

Table 3: Calibrated parameters.

Other calibrated parameters related to steady state are based on actual U.S. and Canadian data. We set the steady state growth rates of output for the United States and Canada, $\mu_{1}$ and $\mu_{2}$, to be $0.34 \%$ per quarter, corresponding to the mean of the data during the period 1973Q1-2012Q3. On the production side, using the 2011 U.S. Input-Output table, we set $\alpha_{22}$ equal to the share of 
intermediate inputs in gross output, which is 0.42 . The home bias parameters for consumption and investment in the United States $\left(\omega_{2}^{C}, \omega_{2}^{I}\right)$ are set to match the export share in total GDP (0.31) and the share of consumption goods and investment goods in Canadian exports (0.21 and 0.12). The fraction of U.S. imported intermediate inputs in the production function $\left(\alpha_{12}\right)$ matches the share of imported intermediate goods in Canadian exports (0.67). Similarly, we calibrate the Canadian home bias for consumption and investment goods parameters $\left(\omega_{1}^{C}, \omega_{1}^{I}\right)$ to match the average import share in total Canadian GDP (0.29), the consumption and investment shares in total import (0.25 and 0.19$)$. The imported intermediate share in the Canadian production function $\left(\alpha_{21}\right)$ is set to match the imported intermediate share in Canadian imports (0.56). These share values are calculated using the 1980-2011 Canadian trade data.

Finally, to test the model's ability to generate endogenous transmission, we shut down both the exogenous correlation and the cointegration in the technology process by setting $\tau=0$ and $\zeta=0.001$ in the baseline estimation, although we also estimate these parameters in the robustness check. ${ }^{18}$

\subsubsection{Impulse Response Matching Step}

The rest of the parameters, including the elasticities of substitution between home and foreign goods in both countries, for which we assume that $\gamma_{1}=\gamma_{2}$, investment adjustment cost, utilization cost, the Jaimovich-Rebelo preference parameter, and the parameters governing U.S. shocks

process, $\left(\gamma, s_{i},\left(\frac{\delta_{2 i}}{\delta_{1 i}}\right), \kappa_{i}, \rho_{22}, \sigma_{2}\right)$ for $i=\{1,2\}$, are estimated by the limited-information Bayesian approach as in Christiano, Trabandt, and Walentin (2010). Let $I R(\Theta)$ denote the theoretical impulse responses given the estimated parameters $\Theta$ and calibrated parameters $\Theta_{-1}$, and $\widehat{I R}$ be the corresponding empirical impulse responses, then $\widehat{I R}$ is treated as "data." The $\widehat{I R}$ includes the impulse responses of U.S. output, consumption, investment and hours to identify the U.S. parameter block including the technology process and demand for Canadian goods. The $\widehat{I R}$ also contains the responses of Canadian output, consumption, investment, hours, net export to output ratio and the terms of trade. Since the technology process is fairly persistent, and including long periods helps to identify parameters, we include the first 30 periods of each response function.

\footnotetext{
${ }^{18}$ We note that this value for $\zeta$ ensures a balanced growth path in the model but the cointegrating relationship is not important for the analysis and model performance.
} 
We define an approximate likelihood of the data, $\widehat{I R}$, as a function of $\Theta$ :

$$
f\left(\widehat{I R} \mid \Theta, V\left(\Theta_{0}, T\right)\right)=\frac{\left|V\left(\Theta_{0}, T\right)\right|^{-\frac{1}{2}}}{(2 \pi)^{\frac{N}{2}}} \exp \left[-\frac{1}{2}(\widehat{I R}-I R)^{\prime} V\left(\Theta_{0}, T\right)^{-1}(\widehat{I R}-I R)\right]
$$

where $\Theta_{0}$ is the true parameter and $V\left(\Theta_{0}, T\right)$ is a known object. Following Christiano, Trabandt, and Walentin (2010), we use the diagonal matrix with the inverse of sample variance of $\widehat{I R}$ along the diagonal as $V\left(\Theta_{0}, T\right)$. Intuitively, with this choice of $V, \Theta$ is chosen so that $I R\left(\Theta \mid \Theta_{-1}\right)$ lies as much as possible within the confidence intervals plotted in Figures 1 and 2. Let $p(\Theta)$ denote prior distributions. Treating this function $f$ as the likelihood of $\widehat{I R}$, it follows that the Bayesian posterior of $\Theta$ conditional on $\widehat{I R}$ and $V\left(\Theta_{0}, T\right)$ is

$$
f\left(\Theta \mid \widehat{I R}, V\left(\Theta_{0}, T\right)\right)=\frac{f\left(\widehat{I R} \mid \Theta, V\left(\Theta_{0}, T\right)\right) p(\Theta)}{f\left(\widehat{I R} \mid V\left(\Theta_{0}, T\right)\right)} .
$$

We use the standard random walk Metropolis-Hastings to estimate $\Theta$ with flat priors.

\subsection{Estimation Results}

This section presents the estimated model. All of the parameters are reported from the posterior distributions obtained from keeping one out of 10 draws in the last 10,000 draws of four chains. ${ }^{19}$

\subsubsection{The Baseline Model}

The first column in Table 4 presents the estimates of our baseline model, which includes our three key features without exogenous technology shock correlation. An important parameter in our three key features, the Jaimovich-Rebelo preference parameter $\left(\kappa_{1}\right)$, which governs the wealth elasticity of labor supply, is estimated tightly around 0.01. This estimate implies a low short-run wealth elasticity of labor supply, consistent with our analysis above. Although other papers in the open economy literature, such as Mendoza (1991), Schmitt-Grohé (1998), García-cicco, Pancrazi, and Uribe (2010), Raffo (2009) and others, assume the GHH preferences, our paper provides empirical evidence for weak wealth effects on labor supply in an open economy context. The second important feature, the elasticity of utilization adjustment, is estimated to be small: 0.03. So, firms can elastically change the level of utilized capital. As shown later, this result is consistent with how Canadian utilization responds to a U.S. technology shock in the data.

\footnotetext{
${ }^{19}$ We confirm that the chains have converged by the trace plots and the scale reduction parameter.
} 


\begin{tabular}{|c|c|c|c|c|c|}
\hline & Parameter & Baseline & $\begin{array}{c}\text { Baseline } \\
\mathrm{w} / \text { correlation }\end{array}$ & $\begin{array}{c}\text { W/o } 3 \text { key } \\
\text { features }\end{array}$ & $\begin{array}{c}\mathrm{W} / \mathrm{o} 3 \text { key } \\
\text { features w/ correlation }\end{array}$ \\
\hline \multicolumn{6}{|c|}{ Canadian block } \\
\hline$\gamma$ & Elasticity of substitution & $\begin{array}{c}1.01 \\
(0.94,1.09)\end{array}$ & $\begin{array}{c}1.02 \\
(0.93,1.15)\end{array}$ & $\begin{array}{c}0.85 \\
(0.79,0.91)\end{array}$ & $\begin{array}{c}0.68 \\
(0.61,0.75)\end{array}$ \\
\hline$s_{1}$ & Investment adjustment cost & $\begin{array}{c}3.69 \\
(1.44,8.04)\end{array}$ & $\begin{array}{c}3.83 \\
(1.44,8.28)\end{array}$ & $\begin{array}{c}1.59 \\
(0.54,4.47)\end{array}$ & $\begin{array}{c}2.40 \\
(0.50,7.07)\end{array}$ \\
\hline$\kappa_{1}$ & Jaimovich-Rebelo parameter & $\begin{array}{c}0.01 \\
(0.01,0.02)\end{array}$ & $\begin{array}{c}0.01 \\
(0.01,0.02)\end{array}$ & & \\
\hline$\delta_{11} / \delta_{21}$ & Utilization elasticity & $\begin{array}{c}0.03 \\
(0.01,0.08) \\
\text { Shock pro }\end{array}$ & $\begin{array}{c}0.03 \\
(0.01,0.08)\end{array}$ & & \\
\hline$\rho_{2}$ & AR coefficient for U.S. shock process & 0.71 & 0.72 & 0.70 & 0.64 \\
\hline & & $(0.67,0.74)$ & $(0.68,0.75)$ & $(0.65,0.75)$ & $(0.57,0.69)$ \\
\hline$\sigma_{2}$ & Standard deviation of U.S. shock & 0.25 & 0.25 & 0.24 & 0.25 \\
\hline & & $(0.22,0.28)$ & $(0.22,0.28)$ & $(0.21,0.28)$ & $(0.22,0.29)$ \\
\hline$\tau$ & Direct technology correlation & & $\begin{array}{c}0.03 \\
(-0.18,0.25)\end{array}$ & & $\begin{array}{c}0.67 \\
(0.36,0.92)\end{array}$ \\
\hline$\zeta$ & Cointegration parameter & & 0.00 & & 0.85 \\
\hline & & & $(0.00,0.01)$ & & $(0.61,0.98)$ \\
\hline \multicolumn{6}{|c|}{ U.S. block } \\
\hline$s_{2}$ & Investment adjustment cost & 0.19 & 0.19 & 0.68 & 0.43 \\
\hline & & $(0.06,0.54)$ & $(0.05,0.54)$ & $(0.19,1.76)$ & $(0.09,1.14)$ \\
\hline$\kappa_{2}$ & Jaimovich-Rebelo parameter & 0.03 & 0.03 & 0.03 & 0.02 \\
\hline & & $(0.02,0.04)$ & $(0.02,0.03)$ & $(0.02,0.03)$ & $(0.02,0.03)$ \\
\hline$\delta_{12} / \delta_{22}$ & Utilization elasticity & 0.18 & 0.19 & 0.09 & 0.06 \\
\hline & & $(0.08,0.32)$ & $(0.09,0.32)$ & $(0.02,0.26)$ & $(0.02,0.15)$ \\
\hline
\end{tabular}

Table 4: Estimation results. The parameter estimates are reported at median of the posterior distributions, and those in parentheses are the $5-95 \%$ confidence intervals calculated with the estimation procedure in Christiano, Trabandt, and Walentin (2010).

The elasticity of substitution parameter is estimated to be 1.01. This estimated value of the elasticity of substitution is within the range of values frequently used in the international business cycle literature. ${ }^{20}$ The investment adjustment cost is estimated to be 3.69 , but the estimate has a wide confidence interval. ${ }^{21}$

Our estimated model matches the observed responses of the Canadian economy well, on average. We first plot in Figure 3a the theoretical impulse responses for U.S. macroeconomic variables with the empirical counterparts. The model can replicate the increase in U.S. output, hours, consumption and investment after a positive permanent technology shock in period one. Figure $3 \mathrm{~b}$ displays the theoretical responses of Canadian variables, together with the empirical responses from the VAR. Consistent with the data, in response to a positive permanent U.S. technology shock, Canadian output, consumption, investment and hours increase and the terms of trade appreciate. The model also captures the gradual boom in the Canadian economy, which is due to the substantial

\footnotetext{
${ }^{20}$ The international macroeconomic literature estimates are typically around 1 , while the estimates in the trade literature range from 6 to 15.

${ }^{21}$ We show in A.4 that the endogenous transmission mechanism is not driven by investment adjustment cost. We estimate a version of the baseline model without investment adjustment costs and find that the model can match the empirical responses well. Finally, the results shown in the paper also do not change much if the model includes habit in consumption.
} 
transmission through international trade. As $\tau$ is set to be zero and $\zeta$ is close to zero, technology in Canada does not increase. Instead, given the gradual increase in U.S. economic activities, the strong endogenous transmission mechanism within the model enables us to replicate the substantial increase in both hours and output in Canada in the short run within 5 to 10 quarters. The success of the model in replicating the data is in stark contrast with the negative results in previous studies such as Schmitt-Grohé (1998) and Justiniano and Preston (2010), which fail to explain the transmission of U.S. shocks across countries.

To assess whether our estimated three key features are consistent with the data, Figure 4 plots the dynamic responses of two important variables for understanding the mechanism, Canadian real wages and capacity utilization, to a positive permanent U.S. technology shock from the model with their empirical counterparts. First, the estimated model matches the empirical responses of the real wage in Canada in the short run. ${ }^{22}$ Real wage is informative about the relative role of labor supply and demand. If there is a large negative wealth effect on labor supply, the shift in labor demand has to be large enough to increase hours in equilibrium, so we should observe a large increase in real wage. On the other hand, if the labor supply curve is flat, the wealth effect is small, labor demand shifts to increase hours, so we should observe a smaller increase in real wage. Empirically, the real wage does not increase much in the short run and increases more in the long run, suggesting that in the short run, the wealth effect may be small, consistent with the estimated model.

Second, our estimated model also predicts a substantial increase in utilization as in the data, as plotted in Figure A1. ${ }^{23}$ There is a clear consistency in direction between the model and the data although the model implies a smaller response of capacity utilization in the first 10 quarters. As variable capacity utilization is one of the key features of our model, this result, if anything, indicates that we understate the importance of variable capacity utilization. ${ }^{24}$

\footnotetext{
${ }^{22}$ The real wage is measured by the total wage and compensation deflated by CPI.

${ }^{23}$ Data on utilization come from Statistics Canada and the Bank of Canada.

${ }^{24}$ In Appendix A, we show that the model predicts an increase in real exports and real imports as in the data. We also examine the real interest rate in Canada, which is a possible mechanism through which the model generates endogenous transmission. For example, Hernandez and Leblebicioglu (2013) highlight that the change in interest rate through working capital channel amplifies the effects of U.S. shocks to Mexico. However, we find that in the context of Canada and the United States, conditional on permanent technology shocks, the movement of the real interest rate is very small, casting doubt on the role of the interest rate in generating endogenous transmission. We also extend the baseline model to include the working capital requirement for wage payment as in Neumeyer and Perri (2005), and we find that endogenous transmission generated by this channel is negligible and the performance of the model is quantitatively similar to our baseline model.
} 

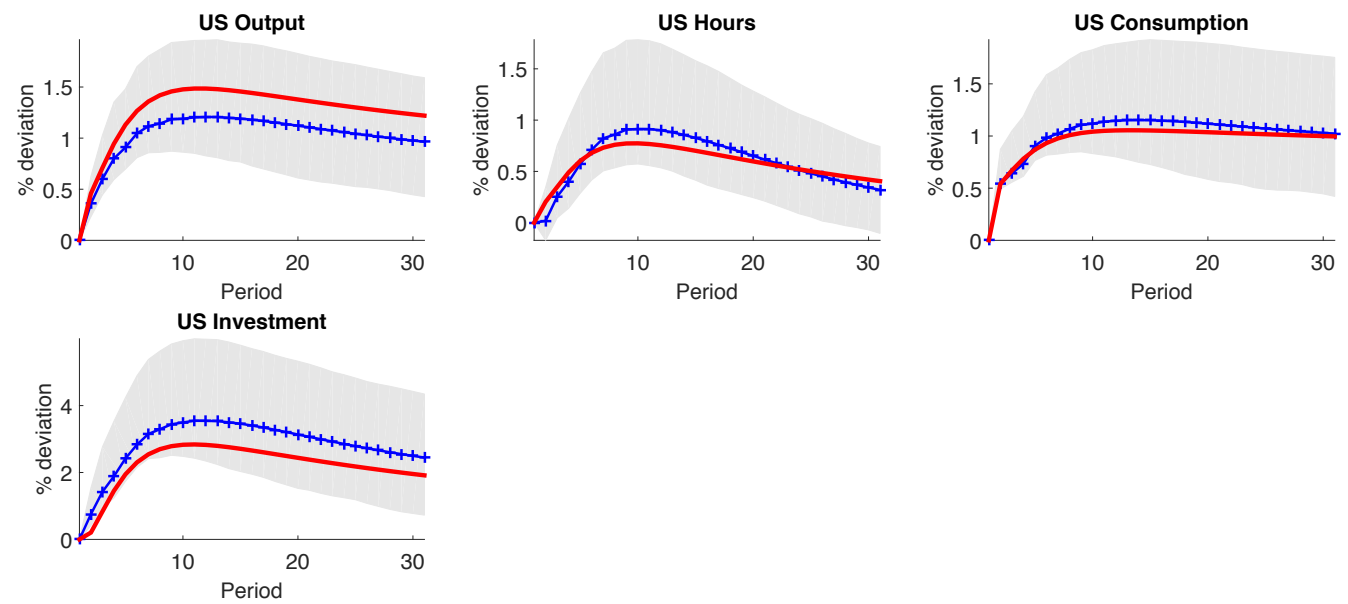

(a) The United States
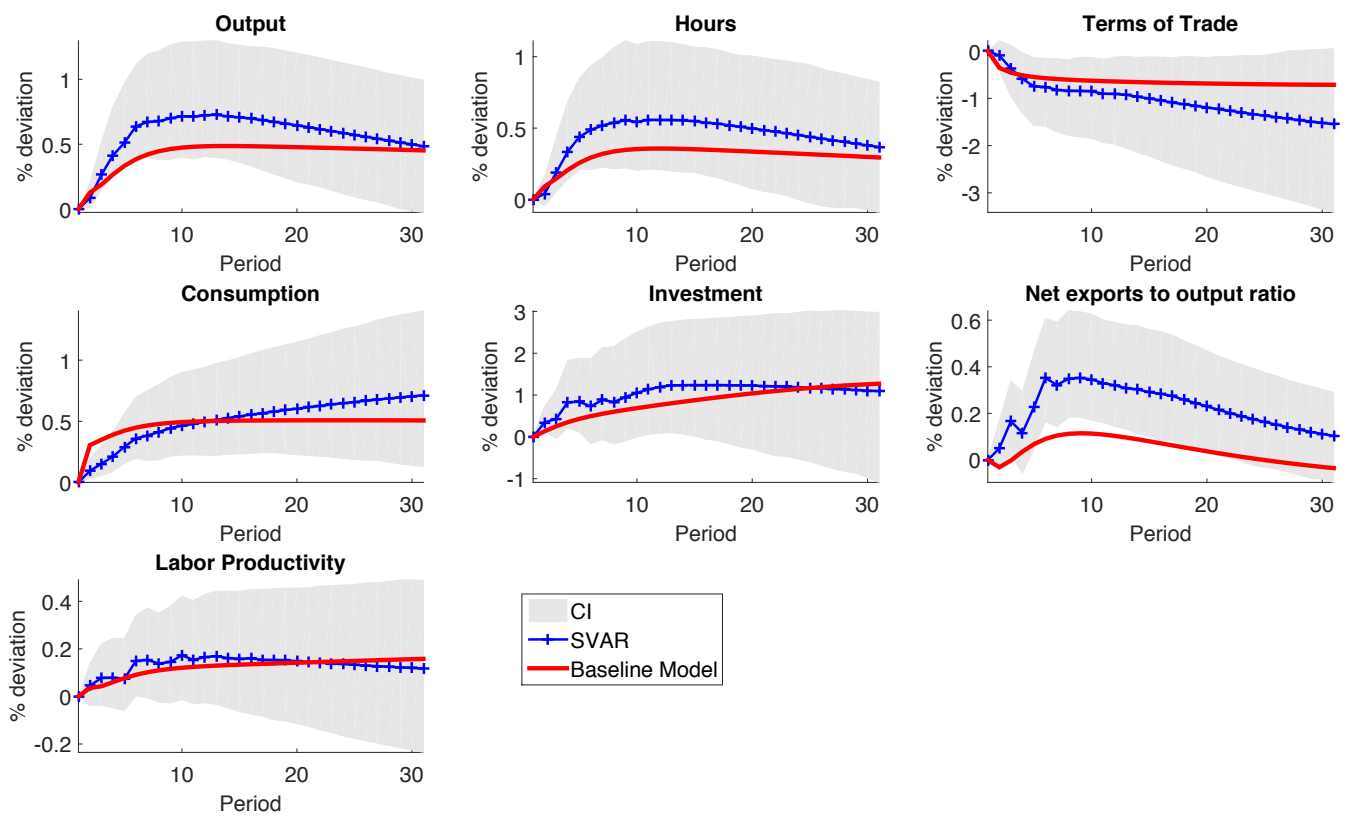

(b) Canada

Figure 3: Baseline model results. Blue lines with plus signs are the point estimates and the shaded areas are the $95 \%$ confidence intervals. Red smooth lines are theoretical responses of the baseline model. 

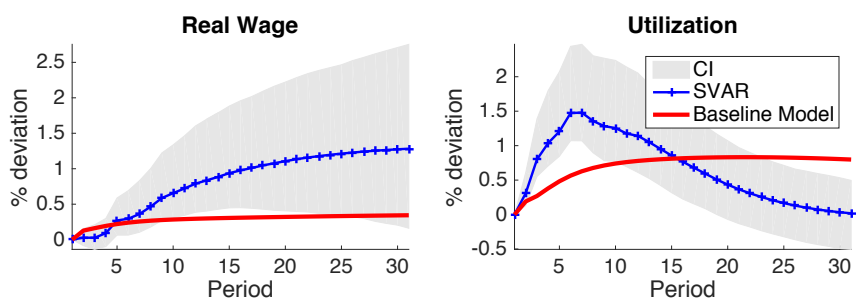

Figure 4: Other Canadian variables. Blue lines with plus signs are the point estimates and the shaded areas are the $95 \%$ confidence intervals. Red smooth lines are theoretical responses of the baseline model.

\subsubsection{The Standard Model}

In contrast with the baseline model, the estimated standard model without the three key features does not generate substantial endogenous transmission and fails to account for the responses of the Canadian economy observed in the data.

We consider the baseline model without the three features: we set $\kappa_{1}=1$ so that the utility function is the standard KPR preference, there is no variable capacity utilization, and there is no imported intermediate input. We estimate this model (called "BKK") using the same method as in the baseline model.
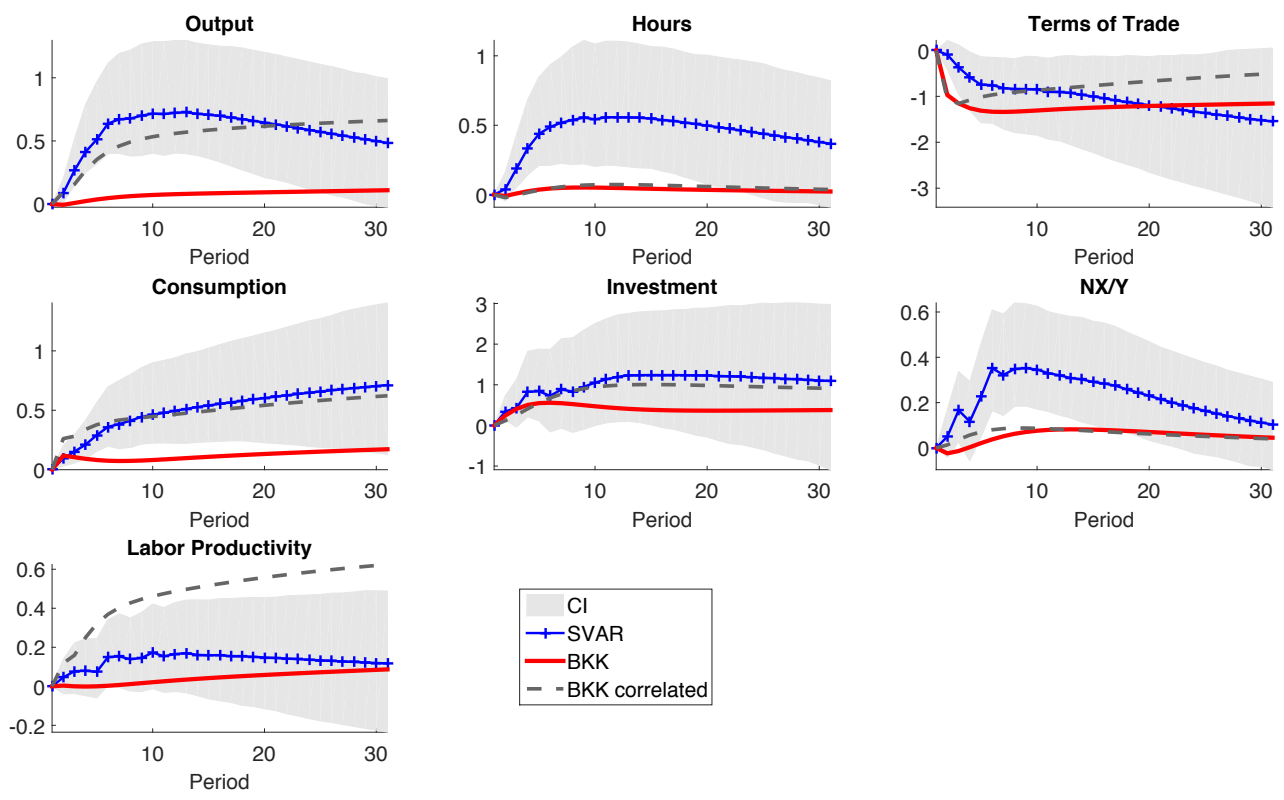

Figure 5: Estimated model without three features: the theoretical impulse responses of Canadian economy to a positive U.S. shock. Lines with plus signs are the point estimates and the shaded areas are the $95 \%$ confidence intervals. Red smooth lines are the responses in the standard (BKK) model. Grey dashed lines are the responses in the simplified model with correlated technology shocks (BKK correlated). 
The estimated parameters and their confidence intervals are reported in column 3 of Table 4 . Figure 5 plots the impulse responses implied by this simplified model and the empirical responses of the macroeconomic variables in Canada. Clearly, the model without the three key features does not capture the dynamic responses of output and hours as well as other aspects of the data, such as consumption and investment. Although the model predicts a gradual increase in Canadian economic activities, the magnitude of the increase is much smaller than that observed in the data. Note that since the estimation tries to match not only output, hours, and consumption but also the terms of trade, the estimated model overpredicts the magnitude of the terms of trade by lowering the elasticity of substitution compared with the baseline model in order to increase hours. Nevertheless, the strong wealth effect coming from the fact that the estimation tries to match consumption causes hours to decrease on impact and increase only slightly in the longer horizons, consistent with our analysis in Section 4. Without changes in hours, output in Canada cannot increase.

\begin{tabular}{lccc}
\hline Model & Log Posterior & Log Likelihood & Marginal LL \\
\hline Baseline & -146.6 & -125.5 & -169.2 \\
Baseline with correlation & -146.0 & -124.2 & -176.4 \\
Without 3 features & -325.1 & -308.6 & -338.8 \\
Without 3 features with correlation & -188.7 & -171.5 & -204.7 \\
With JR preference & -227.2 & -210.8 & -246.4 \\
With intermediate & -307.4 & -290.9 & -320.4 \\
With utilization & -251.2 & -230.1 & -270.2 \\
Baseline with complete market & -172.0 & -151.0 & -198.5 \\
Without 3 features with complete markets & -362.6 & -346.0 & -374.9 \\
\hline Baseline & -207.7 & -186.6 & -231.4 \\
Baseline with wedge & -166.4 & -142.3 & -197.2 \\
Without 3 features with wedge & -350.0 & -330.5 & -370.4 \\
\hline
\end{tabular}

Table 5: Model comparisons. Log likelihood and posterior likelihood are reported at the mean of the draws. Marginal log likelihood is calculated using Geweke's harmonic mean estimator. We additionally include real exports and real imports in the observables when estimating the last three models.

Table 5 reports the log likelihood, log posterior likelihood and marginal log likelihood statistics for each model, which allow us to compare the performance between the baseline model and the standard model without the three key features. ${ }^{25}$ These statistics indicate that given the data, the baseline model is strongly preferred to the model without the three key features.

\section{Sensitivity}

This section shows that all three key features in the model are necessary for the model's success. We discuss the roles of asset market completeness and correlated shocks in generating endogenous

\footnotetext{
${ }^{25}$ See Inoue and Shintani (2015) for the discussion on model comparison.
} 
transmission through international trade. Finally, we demonstrate that a trade wedge reacting to U.S. productivity shocks can help the model to better match the empirical trade flows, but the model still needs the three key features to generate substantial transmission.

\subsection{The Three Key Features}

To demonstrate how our three key features are crucial in generating substantial endogenous transmission, we examine the behavior of the models using one feature at a time. These variants cannot quantitatively generate sufficient endogenous transmission. All the likelihood statistics, including the log posterior, log likelihood and marginal log likelihood statistics, reported in Table 5, suggest that the baseline model is strongly preferred to the model with only one feature. We note that the result that a standard model with intermediate inputs only cannot generate substantial transmission is consistent with previous literature, such as Johnson (2014). The intuition comes from equation (14): intermediate inputs enter as an additional term in the equation that magnifies the effects of the terms of trade on hours worked. However, without low wealth effects of labor supply and variable capital utilization, the effect coming from intermediate inputs is quantitatively small given the large movements in consumption, so hours do not increase much, and the value-added output does not increase much in Canada. ${ }^{26}$

In another exercise, we examine the baseline model, shutting down one feature at a time to investigate the role of each feature. In the interests of space, we plot in Appendix Figure A3 the impulse responses in three cases when one of the features is shut down from the estimated baseline model while other parameters are kept at the baseline estimates. When we shut down the Jaimovich-Rebelo preferences, the model predicts much smaller responses of output and hours. On impact, hours even decrease in Canada due to the strong wealth effect. Without variable capital utilization, the model can replicate the positive responses of output and hours in Canada but falls short in matching the magnitude. Lastly, without imported intermediate inputs, the model also cannot match the large movements of output and hours, consistent with the intuition about the role of imported intermediate goods discussed above. This exercise demonstrates that each of the three features - low wealth effects on labor supply, imported intermediate input and variable capacity utilization - is necessary for the model to generate substantial endogenous transmission. ${ }^{27}$

\footnotetext{
${ }^{26}$ Note that consistent with Johnson (2014), the gross output would increase more in Canada with the existence of intermediate inputs in the standard model.

${ }^{27}$ We also estimate three variants of the baseline models in which there are only two out of three features. The estimated results also indicate the importance of having all three features for the model to generate substantial endogenous transmission.
} 


\subsection{Asset Market Completeness}

The work of Corsetti, Dedola, and Leduc (2008a) and Enders and Müller (2009) suggests that asset market completeness matters for the transmission mechanism in their model. We investigate whether the baseline model's ability to generate substantial endogenous transmission depends on the incomplete financial markets assumption. To this end, we estimate two models: the first is a version of our baseline model with complete markets, and the second is the standard model without the three key features with complete markets. In Table 5, we report the log posterior, log likelihood, and marginal likelihood statistics for the baseline model with complete asset markets and the model without the three key features with complete markets. Consistent with our analysis, the model with three features is preferred over that without three features. The reason is that the baseline model with complete markets is able to replicate the large positive increase in Canadian output and hours and an appreciation of the terms of trade. ${ }^{28}$ In contrast, the version of the complete markets model without the three key features fails to account for the endogenous transmission, as hours and output in Canada barely increase in that model. Consistent with our analysis of equation (14), the relationship between hours and the terms of trade does not change with asset market structures. When the estimation tries to match the movements of consumption and the terms of trade, the model without the three key features under complete asset markets cannot generate a large response of hours as in the data. ${ }^{29}$

\subsection{Correlated Shocks}

Since exogenous correlation of technology shocks may also explain the observed boom in Canada after a positive U.S. technology shock, we let the data speak for itself by estimating a version of the baseline model in which the exogenous correlation of technology ("baseline with correlation") is estimated. The estimated parameters of this version of the baseline model are presented in the second column in Table 4. Notice that the estimated parameters of this model are similar to those of the baseline model. The estimated direct technology correlation $\tau$ is 0.03 , but its $90 \%$ confidence interval includes zero, which means that the shocks are not strongly correlated in the estimated model. Moreover, the cointegration parameter, $\zeta$, is estimated to be tightly close to

\footnotetext{
${ }^{28}$ The impulse responses of the Canadian macroeconomic variables in these two estimated models are presented in Appendix Figure A4.

${ }^{29}$ The asset market structure changes the dynamics of the economy. The complete markets model misses the large increase in Canadian consumption. Matching consumption responses requires a larger value of $\sigma$ than our baseline calibration.
} 
0. The likelihood statistics reported in the last panel of Table 4 are also similar between the two models. Shutting down exogenous correlation of technology while keeping the other estimated parameters, we find that the match of the model does not deteriorate. This result suggests that the estimation assigns a negligible role to the exogenous correlation of technology shocks and a larger role for the endogenous transmission, which is consistent with the empirical evidence in the VAR.

Finally, to address whether exogenous correlation of technology shocks can reconcile the model without our three key features with the data, we re-estimate that model allowing for exogenously correlated technology shock. As shown in the last column of Table 4, the estimated parameter for the cointegrating process, $\zeta$, is 0.85 and for the contemporaneous correlation of shock, $\tau$, is 0.67 , both of which are large and significant. The estimation suggests that exogenous correlation is preferred in order to explain the large responses of output, as suggested by the likelihood statistics. However, as shown in Figure 5, although the strong exogenous correlation of technology shocks helps output in Canada to increase, the response of hours is still much smaller than the empirical counterpart. The model also overpredicts the response of Canadian labor productivity. As reported in Table 5, the likelihood of this model is still smaller than that of the baseline. These results demonstrate two points. First, when the model is not able to generate substantial endogenous transmission, the estimation requires a strong exogenous correlation of technology shocks in order to replicate the data. At the same time, a strong exogenous correlation implies a much larger response of labor productivity compared with the data. Second, when the model has both endogenous and exogenous transmissions of shocks, the estimated model is in line with the empirical evidence, which points to a weak correlation of shocks.

\subsection{Exogenous Wedge}

Although our baseline model generates substantial transmission and matches the data for output, hours, consumption, investment and the terms of trade well, its implied net exports to output ratio is lower than its empirical counterpart. Similarly, although the model generates an increase in the gross trade flows, both real exports and real imports, the increase in the gross trade flows is lower than that in the data. Alessandria, Kaboski, and Midrigan (2013) suggest that trade wedges can be an important mechanism for generating large fluctuations in international trade. ${ }^{30}$ So, we demonstrate in this section that a trade wedge that responds to permanent productivity shocks is

\footnotetext{
${ }^{30}$ Alessandria and Choi (2016) and Alessandria, Lu, and Choi (2016) estimate two country models with trade wedges.
} 
important to help the baseline model to match both the net and gross trade flows better, but it does not change the transmission mechanism of the model significantly: our three key features are still at work to generate substantial comovement between the United States and Canada.

To that end, we augment our baseline model and include an exogenous trade wedge that responds to permanent productivity shocks. This trade wedge loosens the tight link between the terms of trade, real exports, and real imports, imposed by the Armington aggregator of domestic and imported goods. ${ }^{31}$ We allow a stochastic shock $\tau_{i t}$ for $i=\{1,2\}$ to the home bias, which can be interpreted as a shock to trade costs. ${ }^{32}$ For example, consumption goods in country 1 are given by:

$$
C_{1 t}=\left(\left(\tau_{1 t} \omega_{1}^{C}\right)^{\frac{1}{\gamma_{1}}}\left(D_{1 t}^{C}\right)^{\frac{\gamma_{1}-1}{\gamma_{1}}}+\left(1-\tau_{1 t} \omega_{1}^{C}\right)^{\frac{1}{\gamma_{1}}}\left(F_{1 t}^{C}\right)^{\frac{\gamma_{1}-1}{\gamma_{1}}}\right)^{\frac{\gamma_{1}}{\gamma_{1}-1}}
$$

We assume the same specification for investment goods and intermediate inputs for both country 1 and country 2 . The stochastic processes for the wedges, $\tau$, in each country are described by:

$$
\begin{aligned}
& \ln \tau_{1 t}=\rho_{1}^{\tau} \ln \tau_{1 t-1}+\kappa_{1}^{\tau} e_{2 t}, \\
& \ln \tau_{2 t}=\rho_{2}^{\tau} \ln \tau_{2 t-1}+\kappa_{2}^{\tau} e_{2 t},
\end{aligned}
$$

where $\rho_{i}^{\tau}$ for $i=\{1,2\}$ are the persistence of the wedges, and $\kappa_{i}^{\tau}$ govern the variances of the wedge shocks relative to the productivity shock in country $2, e_{2 t} \cdot{ }^{33}$ We estimate the baseline model with $\rho_{2}^{\tau}$ and $\kappa_{2}^{\tau}$, shutting down the reaction of the wedge in country 1 to productivity shocks in country $2 .{ }^{34}$ The observables include all the impulse responses in the baseline, as well as those of Canadian real exports and real imports, to more precisely estimate trade wedges. To highlight the importance of the three key features in generating transmission across countries and examine the role of the trade wedge, we also estimate the model without three features with wedges $\rho_{2}^{\tau}$ and $\kappa_{2}^{\tau}$, in a similar manner.

The last two rows of Table 5 report the log posterior, log likelihood and marginal log likelihood

\footnotetext{
${ }^{31}$ Backus, Kehoe, and Kydland (1995), Levchenko, Lewis, and Tesar (2010), Alessandria, Kaboski, and Midrigan (2013) and others suggest that the Armington aggregator imposes a relationship between real exports, real imports and the terms of trade that is violated in the data, and use "trade wedge" to measure the deviation from this condition in the data. Because we are interested in whether trade wedges affect transmission of shocks across countries, we do not model the sources of trade wedges. These trade wedges can be a combination of multiple frictions. For example, Alessandria, Kaboski, and Midrigan (2013) argue that inventory adjustment is an important source of trade wedges.

${ }^{32}$ An alternative specification is to include $\tau_{i t}$ only on imports. The results of this specification are similar to what we present here.

${ }^{33}$ Since our focus is on U.S. permanent technology shocks, we abstract from the responses of these wedges to Canadian shocks.

${ }^{34}$ The results are quantitatively similar if we also estimate $\rho_{1}^{\tau}$ and $\kappa_{1}^{\tau}$.
} 
of the models with trade wedges. To be comparable, we also report the same statistics for the baseline model when the observable set additionally includes real exports and real imports. The statistics suggest that the model with three key features with wedge is preferred over the baseline model. The reason is that the model with trade wedge with three features can generate both substantial transmission and the large responses of net exports, real exports and real imports. At the same time, the model with trade wedges without three features can only help to obtain large responses of real exports and real imports. ${ }^{35}$ This result suggests that trade wedges are an important mechanism for the model to loosen the tight link between gross trade flows and the terms of trade in the model with the Armington aggregator, so that it helps to reconcile the modelimplied real exports and imports with the data. Importantly, these wedges alone cannot help to generate substantial transmission as observed in the data, and we still need the three key features to reconcile the model with the large empirical responses of hours and output in Canada.

\section{Extension: Model with Nominal Rigidities}

This section extends our analysis to a model with nominal rigidities (NOEM). We show that the three key features are complementary to price rigidity friction to generate substantial transmission through international trade. The model considered is a standard NOEM model, and the details are described in Appendix Section A.8.

We add the empirical impulse responses of Canadian inflation in the observables to estimate the parameters of the model including the sticky price parameter. ${ }^{36}$ The matching of the baseline model with nominal rigidities is displayed in Figure $6{ }^{37}$ The model matches the Canadian responses reasonably well. For example, both hours and output increase as much as the empirical counterparts. The estimated parameters suggest that the three features are important in transmission in the model with price rigidities. When we shut down the three features, also plotted in Figure 6, hours and output increase in Canada after a positive U.S. permanent technology shock but much lower than when the model includes three features. This result suggests that the three key features are complementary in a model with nominal rigidities in generating substantial endogenous transmission.

\footnotetext{
${ }^{35}$ The estimated impulse responses in these models compared with those in the baseline are plotted in the Appendix Figure A6.

${ }^{36}$ We extend the VAR specification for the United States and Canada to estimate the empirical responses of inflation and the nominal interest rate in both countries to a positive U.S. productivity shock.

${ }^{37}$ The estimated model matching for U.S. sides is shown in Appendix Figure A10.
} 

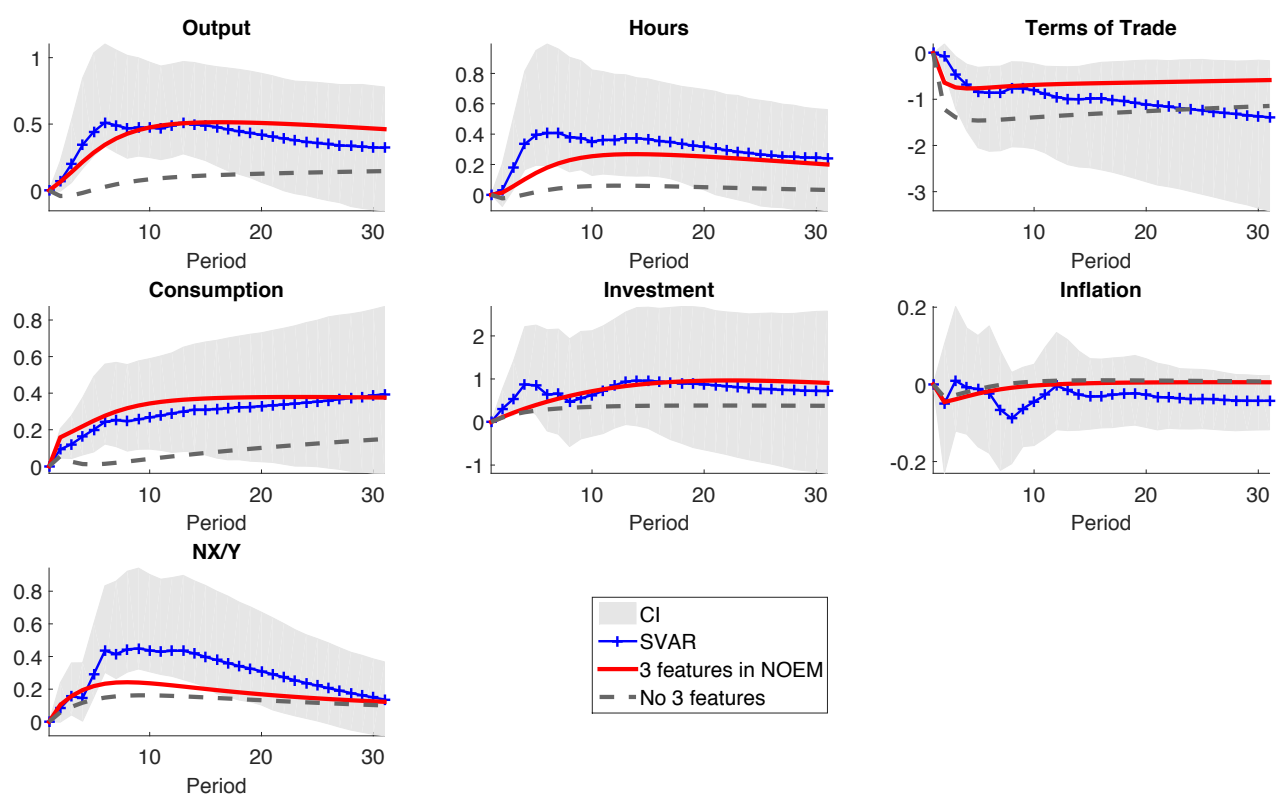

Figure 6: Estimated NOEM model: the theoretical impulse responses of the Canadian economy to a positive U.S. shock. Lines with plus signs are the point estimates and the shaded areas are the $95 \%$ confidence intervals. Smooth red lines are the theoretical responses of the baseline model in a nominal rigidities setting. The dashed grey lines are the responses when we shut down three features but keep the rest of the estimated parameters.

This extension exercise sheds light on the failure of the NOEM model in existing studies to generate large transmission of foreign shocks. For example, Justiniano and Preston (2010) find that the estimated standard NOEM model without capital accumulation using full information methods with U.S. and Canadian data fails to explain the substantial transmission of U.S. shocks to Canada observed in the data. Our approach is conditional analysis but offers a possible reason for their negative result. Since their model does not include the key features that can generate substantial endogenous transmission, it is difficult to generate transmission from the United States to Canada in their model. Although their NOEM model includes nominal rigidities in the form of sticky prices and wages, markup movements associated with these frictions do not necessarily generate large endogenous transmission when trying to match with the data such as the dynamics of inflation and real wage. Our analysis above suggests that the three key features help Justiniano and Preston (2010) to better explain the transmission of U.S. shocks to Canada. 


\section{Conclusion}

This paper examines the transmission mechanism of technology shocks across countries. We document substantial endogenous transmission of technology shocks from the United States to Canada. We show that a standard real international business cycle model augmented with three key features can quantitatively explain a bulk of the transmission observed in U.S.-Canadian data.

More generally, our analysis suggests that other features that affect the labor demand and supply conditions may be able to generate strong endogenous transmission. On the labor supply side, we need features that prevent labor supply from decreasing sharply. This paper uses the low wealth elasticity of labor supply, and another possibility is real wage rigidity, where households need to supply labor given a fixed real wage. On the labor demand side, countercyclical markups such as those generated from the deep habit mechanism can also help to increase labor demand. Judging the relative importance of those features requires additional data and is beyond the scope of this paper; here, we argue that our features are sufficient to explain the observed transmission of permanent U.S. technology shocks to Canada, and are supported by both empirical and theoretical grounds.

Much work can be done to contribute to the international business cycle literature. For example, the "trade comovement" puzzle established by Kose and Yi (2006) and subsequent papers shows that international business cycle models cannot explain the positive relationship between bilateral trade and cross-country correlations. Since our analysis suggests that simple modifications of standard international business cycles can generate substantial international transmission, one can extend our analysis to resolve the trade comovement puzzle. Additionally, this paper focuses on conditional responses, so future work should try to quantitatively account for the unconditional movements of both quantities and international relative prices.

\section{References}

Adolfson, Malin, Stefan Laséen, Jesper Lindé, and Mattias Villani. 2007. "Bayesian estimation of an open economy DSGE model with incomplete pass-through." Journal of International Economics $72(2): 481-511$.

. 2008. "Evaluating an estimated new Keynesian small open economy model." Journal of Economic Dynamics and Control 32 (8):2690-2721. 
Alessandria, George and Horag Choi. 2016. "The Dynamics of the U.S. Trade Balance and Real Exchange Rate: The J Curve and Trade Costs?" Tech. rep.

Alessandria, George, Joseph Kaboski, and Virgiliu Midrigan. 2013. "Trade wedges, inventories, and international business cycles." Journal of Monetary Economics 60 (1):1-20.

Alessandria, George, Dan Lu, and Horag Choi. 2016. "Trade Integration and the Trade Balance in China." Tech. rep.

Ambler, Steve, Emanuela Cardia, and Christian Zimmermann. 2002. "International transmission of the business cycle in a multi-sector model." European Economic Review 46 (2):273-300.

Backus, D, P J Kehoe, and F E Kydland. 1992. "International real business cycles." Journal of Political Economy 100 (4):745-775.

—. 1995. "International business cycles: theory and evidence." In Frontiers in Business Cycle Research (T. Cooley, ed), Princeton University Press.

Baxter, Marianne and Dorsey D Farr. 2005. "Variable capital utilization and international business cycles." Journal of International Economics 65 (2):335-347.

Blanchard, Olivier J and Danny Quah. 1989. "The Dynamic Effects of Aggregate Demand and Supply Disturbances." American Economic Review 79 (4):655-673.

Burstein, Ariel, Christopher Kurz, and Linda Tesar. 2008. "Trade, production sharing, and the international transmission of business cycles." Journal of Monetary Economics 55 (4):775-795.

Christiano, Lawrence J, Martin Eichenbaum, and Charles L Evans. 2005. "Nominal Rigidities and the Dynamic Effects of a Shock to Monetary Policy." Journal of Political Economy 113 (1).

Christiano, Lawrence J, Martin Eichenbaum, and Robert Vigfusson. 2003. "What Happens After a Technology Shock?" Working Paper 9819, National Bureau of Economic Research.

Christiano, Lawrence J, Mathias Trabandt, and Karl Walentin. 2010. "DSGE Models for Monetary Policy Analysis." In Handbook of Monetary Economics, vol. 3, edited by Benjamin M Friedman and Michael Woodford, chap. 7. Elsevier, 1 ed., 285-367.

Corsetti, Giancarlo, Luca Dedola, and Sylvain Leduc. 2008a. "International Risk Sharing and the Transmission of Productivity Shocks." Review of Economic Studies 75 (2):443-473. 
- 2008b. "Productivity, External Balance, and Exchange Rates: Evidence on the Transmission Mechanism among G7 Countries." In NBER International Seminar on Macroeconomics 2006. University of Chicago Press, 117-194.

Enders, Zeno and Gernot J Müller. 2009. "On the international transmission of technology shocks." Journal of International Economics 78 (1):45-59.

Engel, Charles and Jian Wang. 2011. "International trade in durable goods: Understanding volatility, cyclicality, and elasticities." Journal of International Economics 83 (1):37-52.

Fernald, John. 2014. "A Quarterly, Utilization-Adjusted Series on Total Factor Productivity." Working paper.

Fisher, Jonas D M. 2006. "The Dynamic Effects of Neutral and Investment-Specific Technology Shocks." Journal of Political Economy 114 (3).

Gali, Jordi. 1999. "Technology, Employment, and the Business Cycle: Do Technology Shocks Explain Aggregate Fluctuations?" American Economic Review 89 (1):249-271.

García-cicco, Javier, Roberto Pancrazi, and Martín Uribe. 2010. "Real Business Cycles in Emerging Countries?" American Economic Review 100 (December):2510-2531.

Greenwood, Jeremy, Zvi Hercowitz, and Gregory Huffman. 1988. "Investment, Capacity Utilization and the Real business cycle." American Economic Review 78 (3):402-417.

Heathcote, Jonathan and Fabrizio Perri. 2002. "Financial autarky and international business cycles." Journal of Monetary Economics 49 (3):601-627.

Hernandez, Kolver and Ash Leblebicioglu. 2013. "The Transmission of US Shocks to Emerging Markets." Working paper.

Inoue, Atsushi and Mototsugu Shintani. 2015. "Quasi-Bayesian Model Selection." Working paper.

Jaimovich, N and S Rebelo. 2009. "Can news about the future drive the business cycle?" American Economic Review 99 (4):1097-1118.

Johansen, Soren. 1991. "Estimation and Hypothesis Testing of Cointegration Vectors in Gaussian Vector Autoregressive Models." Econometrica 59 (6):1551-1580. 
Johnson, Robert. 2014. "Trade in intermediate inputs and business cycle comovement." American Economic Journal: Macroeconomics 6 (4).

Justiniano, Alejandro and Bruce Preston. 2010. "Can structural small open-economy models account for the influence of foreign disturbances?" Journal of International Economics 81 (1):6174.

King, Robert G, Charles I Plosser, and Sergio T Rebelo. 1988. "Production, growth and business cycles: I. The basic neoclassical model." Journal of Monetary Economics 21 (2-3):195-232.

Kose, M Ayhan and Kei-Mu Yi. 2006. "Can the standard international business cycle model explain the relation between trade and comovement?" Journal of International Economics 68 (2):267295.

Levchenko, Andrei, Logan Lewis, and Linda Tesar. 2010. "The Collapse of International Trade During the 2008-2009 Crisis: In Search of the Smoking Gun." IMF Economic Review 58 (2):214253.

Mendoza, Enrique G. 1991. "Real business cycles in a small open economy." American Economic Review 81 (4):797-818.

Neumeyer, Pablo. and Fabrizio Perri. 2005. "Business cycles in emerging economies: the role of interest rates." Journal of Monetary Economics 52 (2):345-380.

Rabanal, Pau, Juan F Rubio-Ramírez, and Vicente Tuesta. 2011. "Cointegrated TFP processes and international business cycles." Journal of Monetary Economics 58 (2):156-171.

Raffo, Andrea. 2008. "Net exports, consumption volatility and international business cycle models." Journal of International Economics 75 (1):14-29.

—. 2009. "Technology Shocks : Novel Implications for International Business Cycles." Working paper.

Schmitt-Grohé, S. 1998. "The international transmission of economic fluctuations:: Effects of US business cycles on the Canadian economy." Journal of International Economics 44:257-287.

Schmitt-Grohé, Stephanie and Martín Uribe. 2003. "Closing Small Open Economy Models." Journal of International Economics 61:163-185. 
Smets, Frank and Rafael Wouters. 2007. "Shocks and Frictions in US Business Cycles: A Bayesian DSGE Approach." American Economic Review 97 (3):586-606.

Stockman, A C and L L Tesar. 1995. "Tastes and technology in a two-country model of the business cycle: Explaining international comovements." American Economic Review 85 (1):168-185.

\section{A Additional Results}

\section{A.1 Impulse Responses of Additional Variables}

We report here the responses of real exports, real imports and the real interest rate in Canada to a positive permanent U.S. technology shock in the data and the model counterparts. The model falls a little short at matching real exports and real imports. If anything, this suggests that the transmission through international trade is large. We examine a model with durable goods as in Engel and Wang (2011) and inventories as in Alessandria, Kaboski, and Midrigan (2013). We find that the model with inventories helps to generate larger responses of exports and imports on impact compared with the baseline model. Details are available upon request.
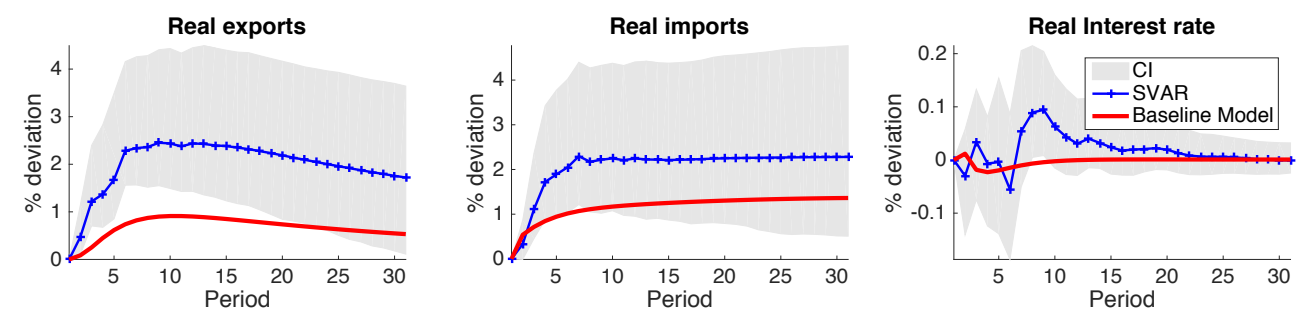

Figure A1: Real exports, real imports and the real interest rate in Canada. Blue lines with plus signs are the point estimates and the shaded areas are the $95 \%$ confidence intervals. Red smooth lines are theoretical responses of the baseline model.

\section{A.2 Parameter Restrictions for the Estimation}

Table A1 documents the parameter restrictions used for the estimation of the models in the paper.

\section{A.3 Importance of Additional Features}

In this appendix, we show how adding one feature into the standard model cannot generate substantial endogenous transmission. Specifically, we estimate three models: standard models with 


\begin{tabular}{ll}
\hline Parameter & Range \\
\hline$\gamma$ & $\mathrm{U}[0.1,100]$ \\
$s_{1}$ & $\mathrm{U}[0,10]$ \\
$\kappa_{1}$ & $\mathrm{U}[0.01,0.99]$ \\
$\left(\delta_{1} / \delta_{2}\right)_{1}$ & $\mathrm{U}[0.01,100]$ \\
$\rho_{2}$ & $\mathrm{U}[-0.5,0.99]$ \\
$\sigma_{2}$ & $\mathrm{U}[0.01,10]$ \\
$\tau$ & $\mathrm{U}[-1,1]$ \\
$\zeta$ & $\mathrm{U}[0.0001,1]$ \\
$s_{2}$ & $\mathrm{U}[0,10]$ \\
$\kappa_{2}$ & $\mathrm{U}[0.01,0.99]$ \\
$\left(\delta_{1} / \delta_{2}\right)_{2}$ & $\mathrm{U}[0.01,100]$ \\
$\rho_{2}^{\tau}$ & $\mathrm{U}[0,0.99]$ \\
$\kappa_{2}^{\tau}$ & $\mathrm{U}[-10,10]$ \\
\hline
\end{tabular}

Table A1: Priors.

Jaimovich-Rebelo preferences (with JR), with variable capacity utilization (with Utilization), with imported intermediate inputs (with Intermediate). The theoretical impulse responses are compared with the empirical evidence in Figure A2.
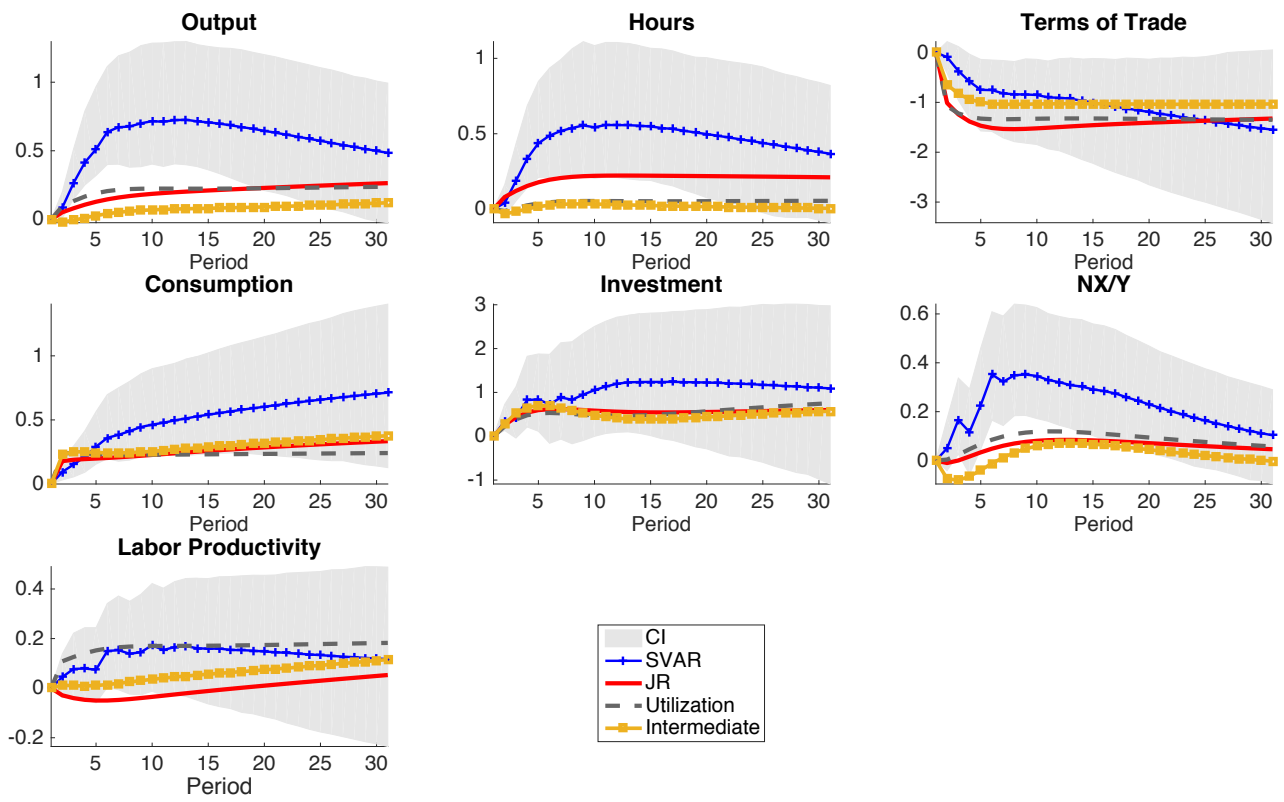

Figure A2: Estimated standard model with one additional feature: the theoretical impulse responses of the Canadian economy to a positive U.S. shock. Lines with plus signs are the point estimates and the shaded areas are the $95 \%$ confidence intervals. Each theoretical model is the standard model with an additional feature.

Figure A3 plots the performance of the model when we shut down one feature while keeping all other parameters at the baseline estimates.

Finally, in Figure A4, we plot the estimated model with complete asset markets. 

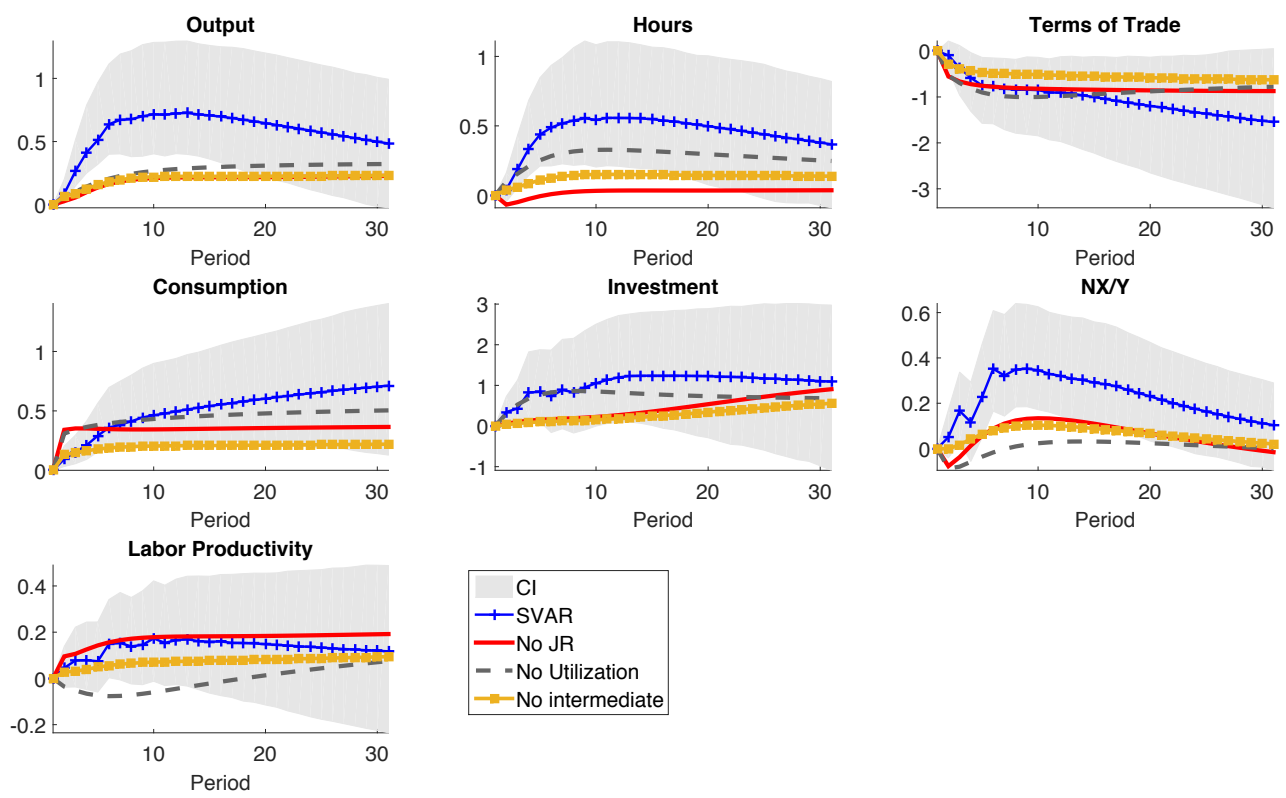

Figure A3: Shutting down one feature: the theoretical impulse responses of the Canadian economy to a positive U.S. shock. Lines with plus signs are the point estimates and the shaded areas are the $95 \%$ confidence intervals. Red smooth lines are the responses in the baseline model without Jaimovich-Rebelo preferences (No JR). Grey dashed lines are the responses in the baseline model without utilization (No Utilization). Yellow lines with squares are the responses in the baseline model without intermediate trade (No Intermediate).

\section{A.4 Investment Adjustment Costs}

We present in this appendix the estimation of the baseline model (with three key features) without investment adjustment costs, shown in Figure A5. Clearly, the investment adjustment cost feature does not change the quantitative prediction of the baseline model in generating endogenous transmission.

\section{A.5 Model with Wedge Shocks}

In Figure A6, we plot the estimation of the model with the trade wedge responding to permanent technology shocks. In particular, we plot the responses of 10 Canadian variables, as well as the responses of real exports and real imports.

\section{A.6 United States-Mexico}

In the empirical exercise for Mexico, we use the same specification as the baseline using the same variables for Mexico. We then estimate the baseline model with three key features by matching the 

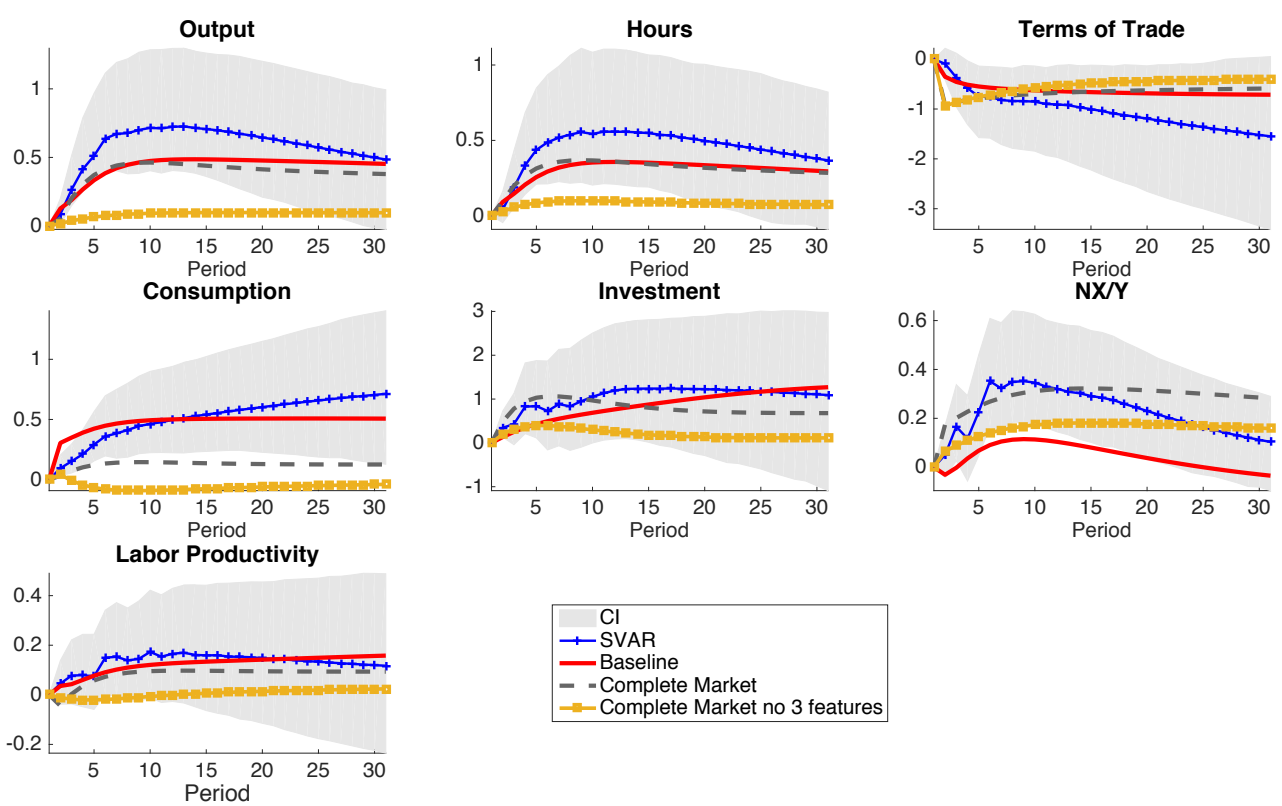

Figure A4: Importance of asset market completeness assumption: the theoretical impulse responses of the Canadian economy to a positive U.S. shock. Lines with plus signs are the point estimates and the shaded areas are the $95 \%$ confidence intervals. Smooth red lines are the theoretical responses of the baseline model. Grey dashed lines are the responses in the baseline model with complete markets. Yellow lines with squares are the baseline model with complete markets but no three features.

model's impulse responses with the empirical counterparts. We plot the result in Figure A7. The model can match reasonably well with the data.

\section{A.7 Identified Investment-Specific Technology Shocks}

We augment the baseline empirical model to include U.S. price of investment as the first variable following Fisher (2006) for the U.S. block. The Canadian block is the same as the baseline. The investment-specific technology shock is the first shock and the neutral technology shock is the second shock identified using the long-run restriction. Figure A8 and Figure A9 plot the impulse responses of U.S. and Canadian macroeconomic variables to these two shocks. The responses of the United States and Canada to a positive U.S. neutral technology shock are similar to the baseline empirical findings. A positive investment-specific technology shock in the United States is significantly expansionary for the United States but less significant for Canada. This rationalizes our focus on neutral technology shocks in the paper.

In addition, we estimate the baseline model augmented with permanent investment-specific 

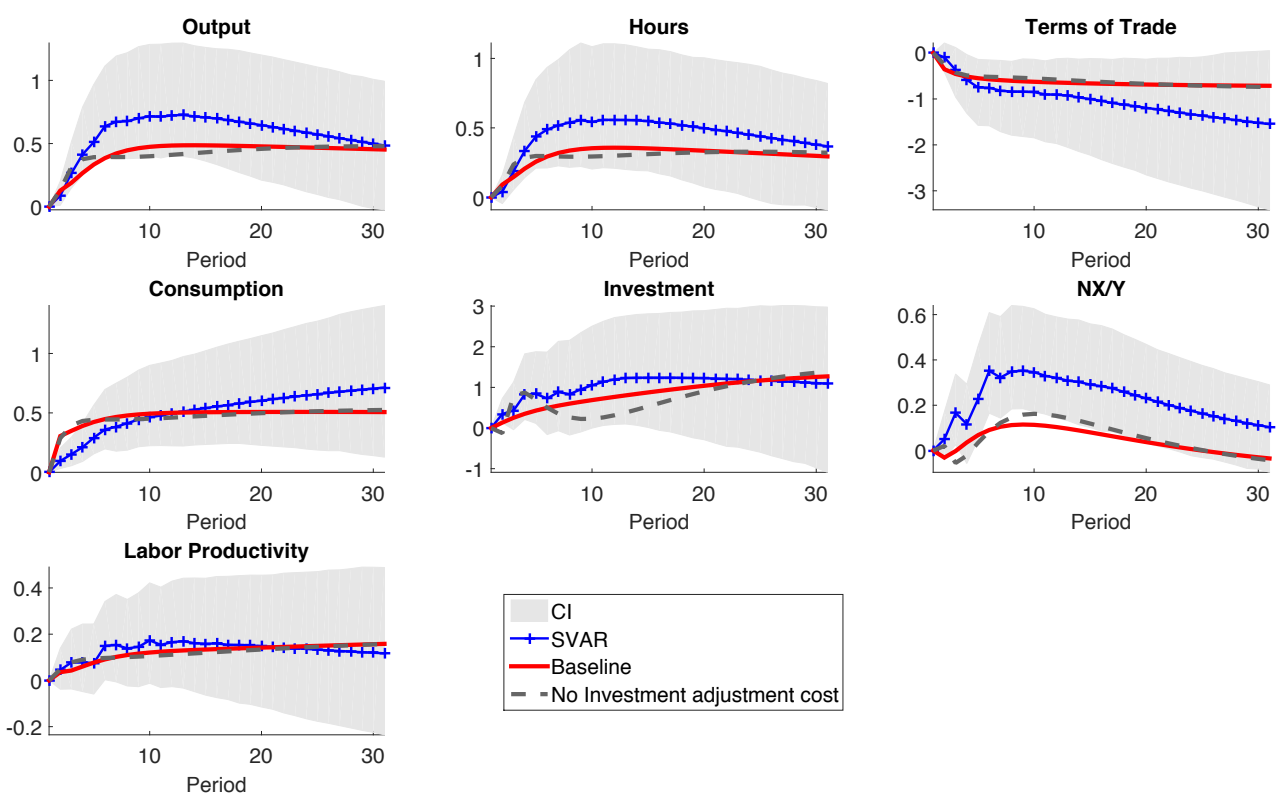

Figure A5: Estimated baseline model without investment adjustment costs: the theoretical impulse responses of the Canadian economy to a positive U.S. shock. Lines with plus signs are the point estimates and the shaded areas are the 95\% confidence intervals. Each theoretical model is the standard model and an additional feature.

technology shocks. In Figure A8 and Figure A9, we plot the baseline model estimated impulse responses against the counterpart when the estimated model has no three key features along with the empirical estimates. The results suggest that the baseline model matches well the responses of the Canadian economy to both neutral U.S. technology shocks and investment-specific technology shocks.

\section{A.8 Model with Nominal Rigidities}

We introduce nominal rigidities in the form of sticky prices into our baseline model. To simplify our exposition, we explain only the structure of country 1 that is different from the baseline model. Country 2 is simply the closed economy version of country 1 . The final good producers combine a continuum of intermediate goods $Y_{1 t}(j)$ where $j \in[0,1]$ to produce final good $Y_{1 t}$ using the following technology:

$$
Y_{1 t}=\left[\int_{0}^{1} Y_{1 t}(j)^{\frac{1}{\eta_{p}}} d j\right]^{\eta_{p}}
$$

where $\eta_{p}$ governs the elasticity of substitution between intermediate goods. The intermediate goods producers are monopolistic firms that produce differentiated intermediate goods $Y_{1 t}(j)$ using the 

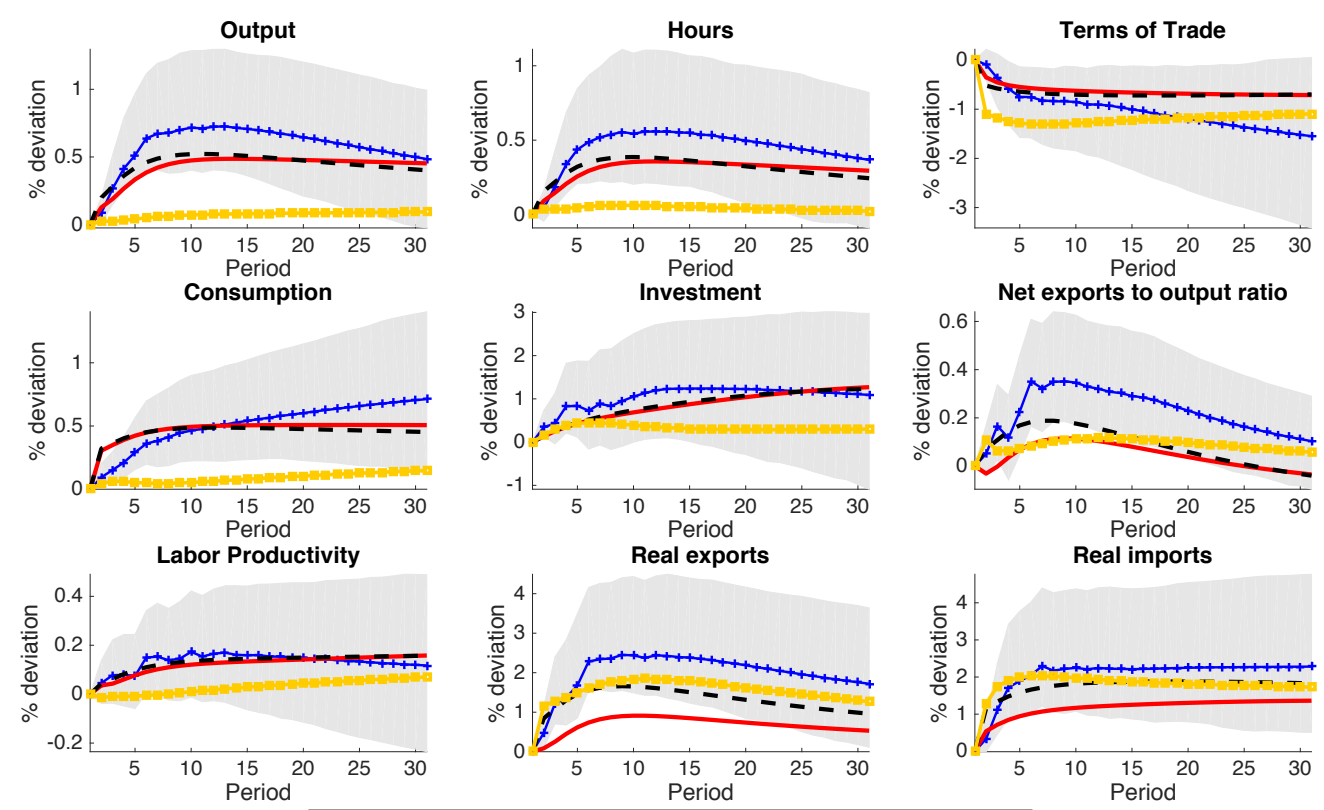

$\mathrm{Cl} \rightarrow$ SVAR —-Baseline Model - - Wedge $-\varpi-$ Wedge w/o 3 features

Figure A6: Estimated baseline model with trade wedges responding to permanent technology shocks: the theoretical impulse responses of the Canadian economy to a positive U.S. shock. Lines with plus signs are the point estimates and the shaded areas are the $95 \%$ confidence intervals. "Baseline" is the baseline model with three features, "Wedge" is the baseline model with trade wedges, and "Wedge w/o 3 features" is the model without three key features with trade wedges.

production function of the following form:

$$
Y_{1 t}(j) \leq\left(\left(u_{1 t} K_{1 t}\right)^{\alpha}\left(Z_{1 t} H_{1 t}\right)^{1-\alpha}\right)^{1-\alpha_{11}-\alpha_{21}}\left(M\left(M_{11 t}, M_{21 t}\right)\right)^{\alpha_{11}+\alpha_{21}}-F C_{1 t},
$$

where $F C_{1 t}$ is the fixed cost included to have zero profits in the steady state. We assume that the intermediate goods firms can change the price with a fixed probability $\theta_{1 p}$ in every period. Lastly, we assume that monetary policy is conducted according to the Taylor-type rule of the form:

$$
\ln R_{t}^{D}=\ln R_{s s}^{D}+s_{\pi} \ln \left(\frac{\pi_{1 t}}{\pi_{1}^{*}}\right)+s_{\Delta Y} \ln \left(\frac{\Delta Y_{1 t}}{\Delta Y_{1 s s}}\right)
$$

where $R_{s s}^{D}$ is the steady state level of nominal interest rate, $\pi_{1}^{*}$ is the steady state level of inflation and $\Delta Y_{1 t}$ is the growth rate of output, and $\Delta Y_{1 s s}$ is the steady state level of $\Delta Y_{1 t}$. 

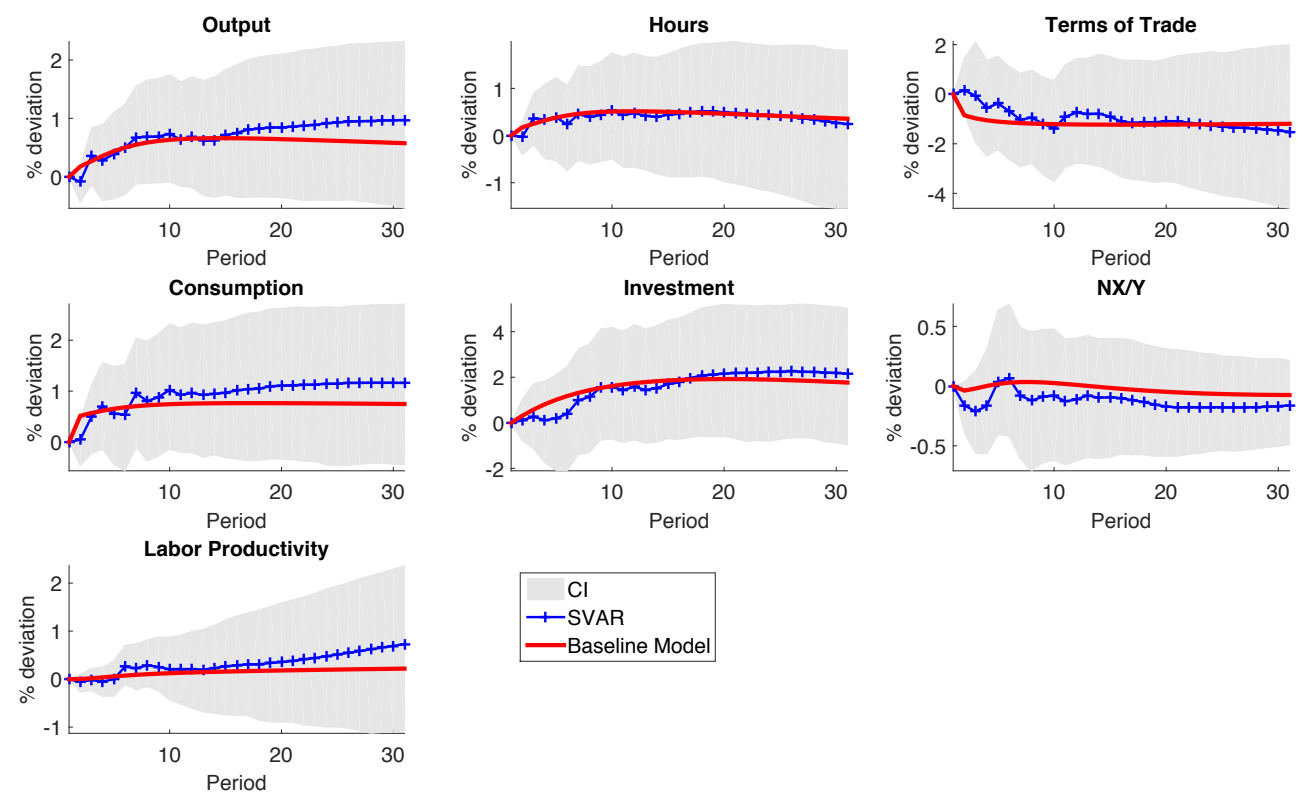

Figure A7: Responses of Mexico's aggregate variables to a positive U.S. neutral technology shock occurring in period 1. Lines with plus signs are the point estimates and the shaded areas are the $95 \%$ confidence intervals. The red lines are the responses in the model with three key features. 

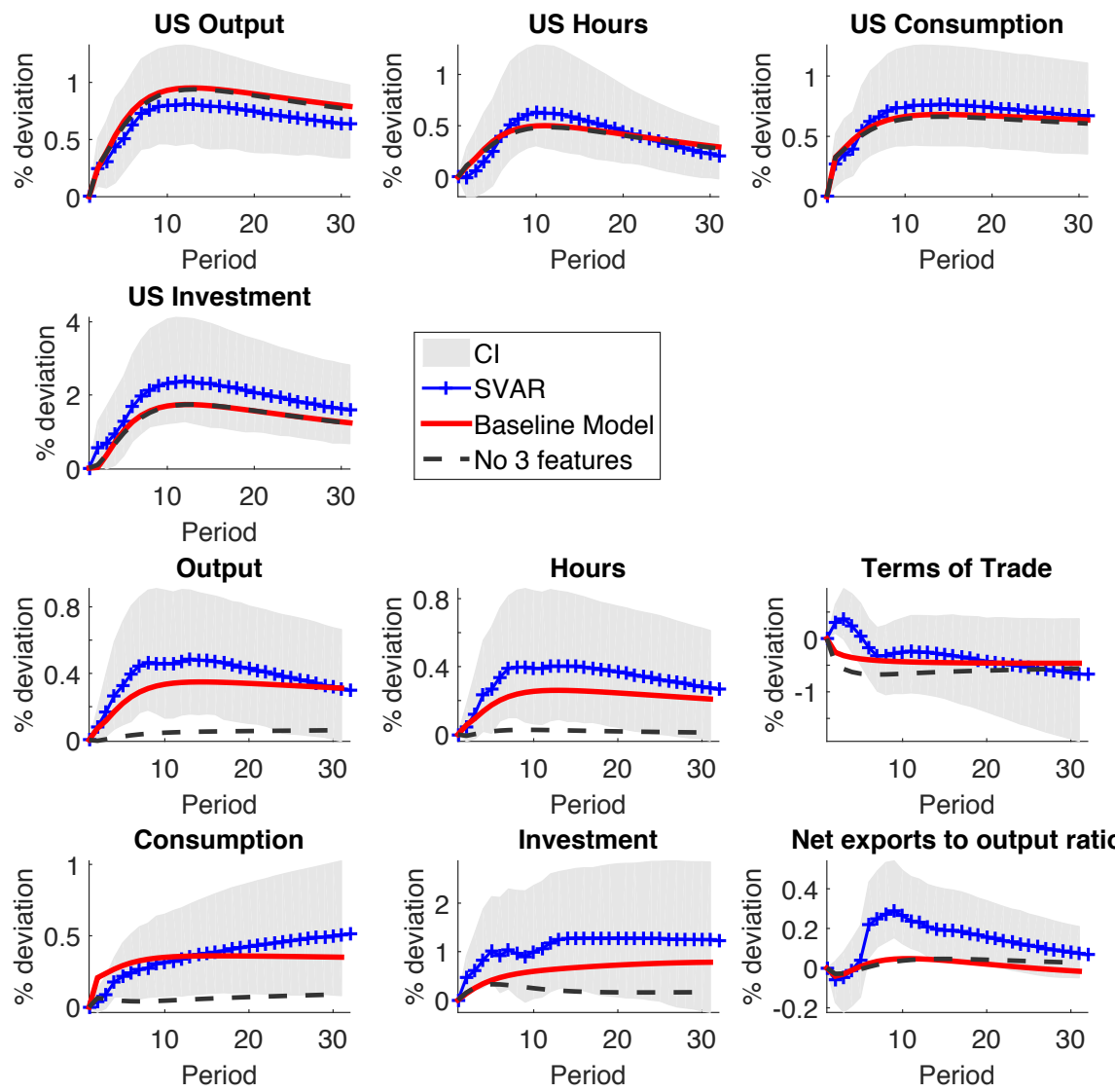

Figure A8: U.S. and Canadian responses to a positive U.S. neutral technology shock occurring in period 1. Lines with plus signs are the point estimates and the shaded areas are the $95 \%$ confidence intervals. The red lines are the responses in the model with three key features. The black dotted lines are the responses in the model with no three features. 

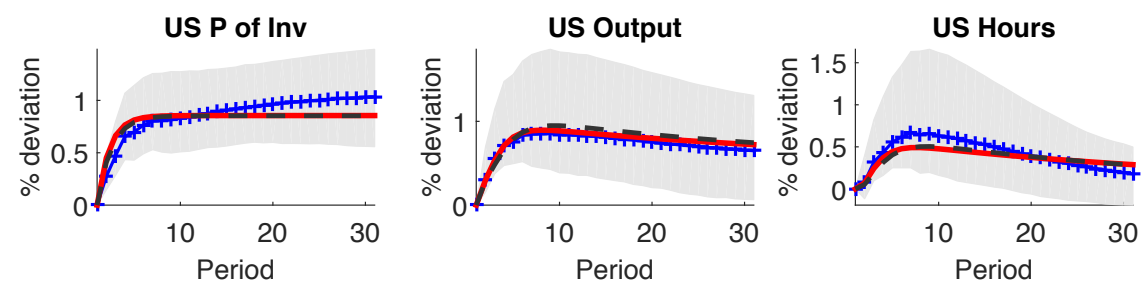

US Consumption
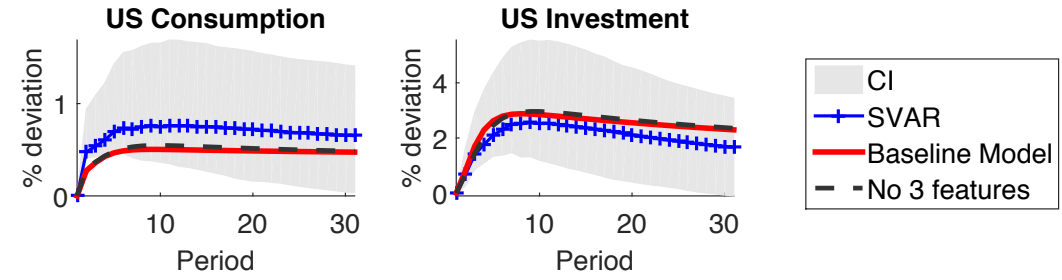

Output
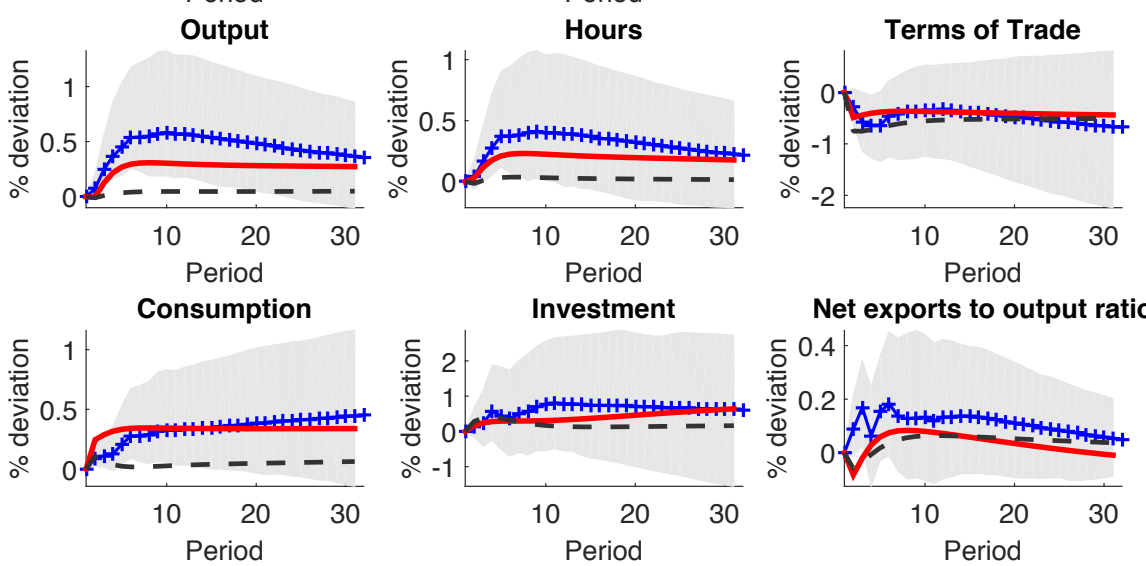

Figure A9: Canadian responses to a positive U.S. investment-specific technology shock occurring in period 1. Lines with plus signs are the point estimates and the shaded areas are the $95 \%$ confidence intervals. The red lines are the responses in the model with three key features. The black dotted lines are the responses in the model with no three features. 

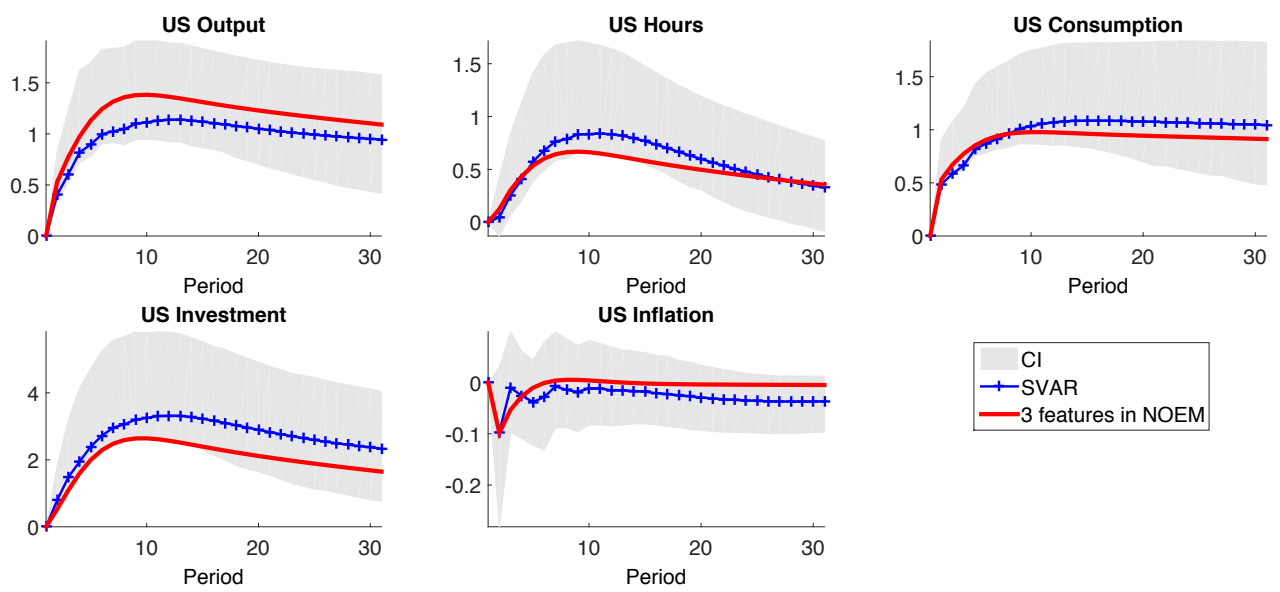

Figure A10: Estimated NOEM: U.S. side. The theoretical impulse responses of U.S. economy to a positive U.S. shock. Lines with plus signs are the point estimates and the shaded areas are the $95 \%$ confidence intervals. Smooth red lines are theoretical responses of the baseline model. 